\title{
Effects of biodiversity on ecosystem functioning: a consensus of current knowledge
}

\author{
Hooper, D U; Chapin III, F S; Ewel, J J; Hector, A; Inchausti, P; Lavorel, S; Lawton, J \\ H; Lodge, D M; Loreau, M; Naeem, S; Schmid, B; Setälä, H; Symstad, A J;
}

Vandermeer, J; Wardle, D A

Hooper, D U; Chapin III, F S; Ewel, J J; Hector, A; Inchausti, P; Lavorel, S; Lawton, J H; Lodge, D M; Loreau, M; Naeem, S; Schmid, B; Setälä, H; Symstad, A J; Vandermeer, J; Wardle, D A. Effects of biodiversity on ecosystem functioning: a consensus of current knowledge. Ecological Monographs 2005, 75(1):3-35.

Postprint available at:

http://www.zora.unizh.ch

Posted at the Zurich Open Repository and Archive, University of Zurich.

http://www.zora.unizh.ch

Originally published at:

Ecological Monographs 2005, 75(1):3-35 


\title{
Effects of biodiversity on ecosystem functioning: a consensus of current knowledge
}

\begin{abstract}
Humans are altering the composition of biological communities through a variety of activities that increase rates of species invasions and species extinctions, at all scales, from local to global. These changes in components of the Earth's biodiversity cause concern for ethical and aesthetic reasons, but they also have a strong potential to alter ecosystem properties and the goods and services they provide to humanity. Ecological experiments, observations, and theoretical developments show that ecosystem properties depend greatly on biodiversity in terms of the functional characteristics of organisms present in the ecosystem and the distribution and abundance of those organisms over space and time. Species effects act in concert with the effects of climate, resource availability, and disturbance regimes in influencing ecosystem properties. Human activities can modify all of the above factors; here we focus on modification of these biotic controls.
\end{abstract}

The scientific community has come to a broad consensus on many aspects of the relationship between biodiversity and ecosystem functioning, including many points relevant to management of ecosystems. Further progress will require integration of knowledge about biotic and abiotic controls on ecosystem properties, how ecological communities are structured, and the forces driving species extinctions and invasions. To strengthen links to policy and management, we also need to integrate our ecological knowledge with understanding of the social and economic constraints of potential management practices. Understanding this complexity, while taking strong steps to minimize current losses of species, is necessary for responsible management of Earth's ecosystems and the diverse biota they contain.

Based on our review of the scientific literature, we are certain of the following conclusions:

1)Species' functional characteristics strongly influence ecosystem properties. Functional characteristics operate in a variety of contexts, including effects of dominant species, keystone species, ecological engineers, and interactions among species (e.g., competition, facilitation, mutualism, disease, and predation). Relative abundance alone is not always a good predictor of the ecosystem-level importance of a species, as even relatively rare species (e.g., a keystone predator) can strongly influence pathways of energy and material flows.

2)Alteration of biota in ecosystems via species invasions and extinctions caused by human activities has altered ecosystem goods and services in many well-documented cases. Many of these changes are difficult, expensive, or impossible to reverse or fix with technological solutions.

3)The effects of species loss or changes in composition, and the mechanisms by which the effects manifest themselves, can differ among ecosystem properties, ecosystem types, and pathways of potential community change.

4)Some ecosystem properties are initially insensitive to species loss because (a) ecosystems may have multiple species that carry out similar functional roles, (b) some species may contribute relatively little to ecosystem properties, or (c) properties may be primarily controlled by abiotic environmental conditions.

5)More species are needed to insure a stable supply of ecosystem goods and services as spatial and temporal variability increases, which typically occurs as longer time periods and larger areas are considered.

We have high confidence in the following conclusions: 
1)Certain combinations of species are complementary in their patterns of resource use and can increase average rates of productivity and nutrient retention. At the same time, environmental conditions can influence the importance of complementarity in structuring communities. Identification of which and how many species act in a complementary way in complex communities is just beginning.

2)Susceptibility to invasion by exotic species is strongly influenced by species composition and, under similar environmental conditions, generally decreases with increasing species richness. However, several other factors, such as propagule pressure, disturbance regime, and resource availability also strongly influence invasion success and often override effects of species richness in comparisons across different sites or ecosystems.

3)Having a range of species that respond differently to different environmental perturbations can stabilize ecosystem process rates in response to disturbances and variation in abiotic conditions. Using practices that maintain a diversity of organisms of different functional effect and functional response types will help preserve a range of management options.

Uncertainties remain and further research is necessary in the following areas:

1)Further resolution of the relationships among taxonomic diversity, functional diversity, and community structure is important for identifying mechanisms of biodiversity effects.

2)Multiple trophic levels are common to ecosystems but have been understudied in biodiversity/ecosystem functioning research. The response of ecosystem properties to varying composition and diversity of consumer organisms is much more complex than responses seen in experiments that vary only the diversity of primary producers.

3)Theoretical work on stability has outpaced experimental work, especially field research. We need long-term experiments to be able to assess temporal stability, as well as experimental perturbations to assess response to and recovery from a variety of disturbances. Design and analysis of such experiments must account for several factors that covary with species diversity.

4)Because biodiversity both responds to and influences ecosystem properties, understanding the feedbacks involved is necessary to integrate results from experimental communities with patterns seen at broader scales. Likely patterns of extinction and invasion need to be linked to different drivers of global change, the forces that structure communities, and controls on ecosystem properties for the development of effective management and conservation strategies.

5)This paper focuses primarily on terrestrial systems, with some coverage of freshwater systems, because that is where most empirical and theoretical study has focused. While the fundamental principles described here should apply to marine systems, further study of that realm is necessary.

Despite some uncertainties about the mechanisms and circumstances under which diversity influences ecosystem properties, incorporating diversity effects into policy and management is essential, especially in making decisions involving large temporal and spatial scales. Sacrificing those aspects of ecosystems that are difficult or impossible to reconstruct, such as diversity, simply because we are not yet certain about the extent and mechanisms by which they affect ecosystem properties, will restrict future management options even further. It is incumbent upon ecologists to communicate this need, and the values that can derive from such a perspective, to those charged with economic and policy decision-making. 


\title{
ESA Report
}

\section{EFFECTS OF BIODIVERSITY ON ECOSYSTEM FUNCTIONING: A CONSENSUS OF CURRENT KNOWLEDGE}

\author{
D. U. Hooper,,${ }^{1,16}$ F. S. Chapin, III, ${ }^{2}$ J. J. Ewel, ${ }^{3}$ A. Hector,${ }^{4}$ P. Inchausti,${ }^{5}$ S. Lavorel ${ }^{6}$ J. H. Lawton, \\ D. M. Lodge, ${ }^{8}$ M. Loreau, ${ }^{9}$ S. Naeem, ${ }^{10}$ B. Schmid,${ }^{4}$ H. Setälä,,${ }^{11}$ A. J. Symstad,${ }^{12}$ \\ J. VANDERMEER, ${ }^{13}$ AND D. A. WARDLE ${ }^{14,15}$ \\ ${ }^{1}$ Department of Biology, Western Washington University, Bellingham, Washington 98225 USA \\ ${ }^{2}$ Institute of Arctic Biology, University of Alaska, Fairbanks, Alaska 99775 USA \\ ${ }^{3}$ Institute of Pacific Islands Forestry, Pacific Southwest Research Station, USDA Forest Service, 1151 Punchbowl Street \\ Room 323, Honolulu, Hawaii 96813 USA \\ ${ }^{4}$ Institute of Environmental Sciences, University of Zurich, Winterthurerstrasse 190, CH-8057 Zürich, Switzerland \\ ${ }^{5}$ CEBC-CNRS, 79360 Beauvoir-sur-Niort, France \\ ${ }^{6}$ Laboratoire d'Ecologie Alpine, CNRS UMR 5553, Université J. Fourier, BP 53, 38041 Grenoble Cedex 9, France \\ ${ }^{7}$ Natural Environment Research Council, Polaris House, North Star Avenue, Swindon SN2 1EU, UK \\ ${ }^{8}$ Department of Biological Sciences, P.O. Box 369, University of Notre Dame, Notre Dame, Indiana 46556-0369 USA \\ ${ }^{9}$ Laboratoire d'Ecologie, UMR 7625, Ecole Normale Supérieure, 46 rue d'Ulm, 75230 Paris Cedex 05, France \\ ${ }^{10}$ Department of Ecology, Evolution and Environmental Biology, Columbia University, 1200 Amsterdam Avenue, \\ New York, New York 10027 USA \\ ${ }^{11}$ University of Helsinki, Department of Ecological and Environmental Sciences, Niemenkatu 73, FIN-15140 Lahti, Finland \\ ${ }^{12}$ U.S. Geological Survey, Mount Rushmore National Memorial, 13000 Highway 244, Keystone, South Dakota 57751 USA \\ ${ }^{13}$ Department of Biology, University of Michigan, Ann Arbor, Michigan 48109 USA \\ ${ }^{14}$ Landcare Research, P.O. Box 69, Lincoln, New Zealand \\ ${ }^{15}$ Department of Forest Vegetation Ecology, Swedish University of Agricultural Sciences, SE901-83, Umeå, Sweden
}

Abstract. Humans are altering the composition of biological communities through a variety of activities that increase rates of species invasions and species extinctions, at all scales, from local to global. These changes in components of the Earth's biodiversity cause concern for ethical and aesthetic reasons, but they also have a strong potential to alter ecosystem properties and the goods and services they provide to humanity. Ecological experiments, observations, and theoretical developments show that ecosystem properties depend greatly on biodiversity in terms of the functional characteristics of organisms present in the ecosystem and the distribution and abundance of those organisms over space and time. Species effects act in concert with the effects of climate, resource availability, and disturbance regimes in influencing ecosystem properties. Human activities can modify all of the above factors; here we focus on modification of these biotic controls.

The scientific community has come to a broad consensus on many aspects of the relationship between biodiversity and ecosystem functioning, including many points relevant to management of ecosystems. Further progress will require integration of knowledge about biotic and abiotic controls on ecosystem properties, how ecological communities are structured, and the forces driving species extinctions and invasions. To strengthen links to policy and management, we also need to integrate our ecological knowledge with understanding of the social and economic constraints of potential management practices. Understanding this complexity, while taking strong steps to minimize current losses of species, is necessary for responsible management of Earth's ecosystems and the diverse biota they contain.

Manuscript received 2 June 2004; accepted 7 June 2004; final version received 7 July 2004. Corresponding Editor (ad hoc): J. S. Denslow. This article is a committee report commissioned by the Governing Board of the Ecological Society of America. Reprints of this 33-page ESA report are available for $\$ 5.00$ each, either as pdf files or as hard copy. Prepayment is required. Order reprints from the Ecological Society of America, Attention: Reprint Department, 1707 H Street, N.W., Suite 400, Washington, DC 20006 USA (e-mail: esaHQ@esa.org).

${ }^{16}$ E-mail: hooper@biol.wwu.edu 
Based on our review of the scientific literature, we are certain of the following conclusions:

1) Species' functional characteristics strongly influence ecosystem properties. Functional characteristics operate in a variety of contexts, including effects of dominant species, keystone species, ecological engineers, and interactions among species (e.g., competition, facilitation, mutualism, disease, and predation). Relative abundance alone is not always a good predictor of the ecosystem-level importance of a species, as even relatively rare species (e.g., a keystone predator) can strongly influence pathways of energy and material flows.

2) Alteration of biota in ecosystems via species invasions and extinctions caused by human activities has altered ecosystem goods and services in many well-documented cases. Many of these changes are difficult, expensive, or impossible to reverse or fix with technological solutions.

3 ) The effects of species loss or changes in composition, and the mechanisms by which the effects manifest themselves, can differ among ecosystem properties, ecosystem types, and pathways of potential community change.

4) Some ecosystem properties are initially insensitive to species loss because (a) ecosystems may have multiple species that carry out similar functional roles, (b) some species may contribute relatively little to ecosystem properties, or (c) properties may be primarily controlled by abiotic environmental conditions.

5) More species are needed to insure a stable supply of ecosystem goods and services as spatial and temporal variability increases, which typically occurs as longer time periods and larger areas are considered.

We have high confidence in the following conclusions:

1) Certain combinations of species are complementary in their patterns of resource use and can increase average rates of productivity and nutrient retention. At the same time, environmental conditions can influence the importance of complementarity in structuring communities. Identification of which and how many species act in a complementary way in complex communities is just beginning.

2) Susceptibility to invasion by exotic species is strongly influenced by species composition and, under similar environmental conditions, generally decreases with increasing species richness. However, several other factors, such as propagule pressure, disturbance regime, and resource availability also strongly influence invasion success and often override effects of species richness in comparisons across different sites or ecosystems.

3) Having a range of species that respond differently to different environmental perturbations can stabilize ecosystem process rates in response to disturbances and variation in abiotic conditions. Using practices that maintain a diversity of organisms of different functional effect and functional response types will help preserve a range of management options.

Uncertainties remain and further research is necessary in the following areas:

1) Further resolution of the relationships among taxonomic diversity, functional diversity, and community structure is important for identifying mechanisms of biodiversity effects.

2) Multiple trophic levels are common to ecosystems but have been understudied in biodiversity/ecosystem functioning research. The response of ecosystem properties to varying composition and diversity of consumer organisms is much more complex than responses seen in experiments that vary only the diversity of primary producers.

3) Theoretical work on stability has outpaced experimental work, especially field research. We need long-term experiments to be able to assess temporal stability, as well as experimental perturbations to assess response to and recovery from a variety of disturbances. Design and analysis of such experiments must account for several factors that covary with species diversity.

4) Because biodiversity both responds to and influences ecosystem properties, understanding the feedbacks involved is necessary to integrate results from experimental communities with patterns seen at broader scales. Likely patterns of extinction and invasion need to be linked to different drivers of global change, the forces that structure communities, and controls on ecosystem properties for the development of effective management and conservation strategies.

5) This paper focuses primarily on terrestrial systems, with some coverage of freshwater systems, because that is where most empirical and theoretical study has focused. While the 
fundamental principles described here should apply to marine systems, further study of that realm is necessary.

Despite some uncertainties about the mechanisms and circumstances under which diversity influences ecosystem properties, incorporating diversity effects into policy and management is essential, especially in making decisions involving large temporal and spatial scales. Sacrificing those aspects of ecosystems that are difficult or impossible to reconstruct, such as diversity, simply because we are not yet certain about the extent and mechanisms by which they affect ecosystem properties, will restrict future management options even further. It is incumbent upon ecologists to communicate this need, and the values that can derive from such a perspective, to those charged with economic and policy decision-making.

Key words: biodiversity; complementary resource use; ecosystem goods and services; ecosystem processes; ecosystem properties; functional characteristics; functional diversity; net primary production; sampling effect; species extinction; species invasions; species richness; stability.

\section{INTRODUCTION}

\section{A. The context: human effects on biodiversity}

Human activities have been and are continuing to change the environment on local and global scales. Many of these alterations are leading to dramatic changes in the biotic structure and composition of ecological communities, either from the loss of species or from the introduction of exotic species. Such changes can readily change the ways in which ecosystems work. Altered biodiversity has led to widespread concern for a number of both market (e.g., ecotourism, "mining", for medicines) and non-market (e.g., ethical, aesthetic) reasons (Barbier et al. 1995, Kunin and Lawton 1996, Schwartz et al. 2000, Hector et al. 2001b, Minns et al. 2001, Sax and Gaines 2003). These reasons are compelling in their own right, but ecologists have raised additional concerns: What is the effect of changing biodiversity on ecosystem properties, such as productivity, carbon storage, hydrology, and nutrient cycling? The obvious follow-up question is: What are the consequences of such largely anthropogenic changes in biodiversity on the goods and services that ecosystems provide to humans? If altered biodiversity affects ecosystem properties, is there a point at which changes in properties might adversely influence human welfare?

While global extinction of a species is clearly an important conservation concern, local species extinctions or even large changes in abundances have as much potential to affect ecosystem properties (e.g., Zimov et al. 1995). Local extinctions and large effects of introduced species are more common than global extinctions and can be very difficult to reverse, as seen with many attempts to reintroduce species or eradicate invasive exotics (Enserink 1999, Finkel 1999, Kaiser 1999, Malakoff 1999, Stokstad 1999, Stone 1999, Sax and Gaines 2003). These problems affect both managed and unmanaged ecosystems (Pimentel et al. 1992).

The effects of biodiversity loss or changes in community composition on the functioning of ecosystems have been the focus of much ecological research, with an explosion of research over the past decade (Schulze and Mooney 1993, Kinzig et al. 2002, Loreau et al. $2002 b$ ). In spite of this effort, however, there remain important aspects that are still not well understood. There has been substantial debate within the ecological community on the interpretation of some recent research and whether the findings from these studies are as important as other factors that are well known to correlate with ecosystem functioning in nature. Many of the authors of this paper have been on different sides of this debate. Our goals here are to summarize a consensus view for the ecological community of current understandings of the relationships between biodiversity and ecosystem functioning with an eye to uncertainties and future directions that can help to address some of these uncertainties. We review the scientific evidence for links between biodiversity and ecosystem functioning, including theoretical, observational, and experimental results, and we link the scientific studies to potential management and policy implications. We particularly focus on research over the past decade that treats quantitative aspects of biodiversity, since earlier work has been summarized elsewhere (Schulze and Mooney 1993). We highlight areas of consensus among ecologists, point out areas of disagreement, and suggest questions for future study.

\section{B. Definitions}

Clear discussion of the effects of biodiversity on ecosystem functioning requires clear definitions of these two terms. The term biodiversity encompasses a broad spectrum of biotic scales, from genetic variation within species to biome distribution on the planet (Wilson 1992, Gaston 1996, Purvis and Hector 2000, Mooney 2002). Biodiversity can be described in terms of numbers of entities (how many genotypes, species, or ecosystems), the evenness of their distribution, the differences in their functional traits (Box 1), and their interactions. While biodiversity has often been used as a synonym for species richness (the number of species present), different components of biodiversity (e.g., 


\section{Box 1. Functional traits, functional types, and functional diversity}

An understanding of how changes in species richness and composition, and biodiversity in general, influence ecosystem properties requires an understanding of the functional traits of the species involved. By definition, functional traits are those that influence ecosystem properties or species' responses to environmental conditions. Species are often grouped together according to their functional traits to understand general mechanisms or to make studies of complex systems more tractable. Functional types (aka functional groups) are, at first glance, a relatively simple concept. A functional type is a set of species that have similar effects on a specific ecosystem process or similar responses to environmental conditions. Functional types are similar to the guild concept from animal community ecology (Root 1967, Simberloff and Dayan 1991, Wilson 1999) and to niche concepts (Leibold 1995). Although functional types can be quite useful, the practice of defining them and quantifying functional diversity can be difficult. There are four basic reasons for this:

1) Organisms' effects on ecosystem properties generally fall along a continuous gradient, not into distinct groups. Thus, designating functional groups may require arbitrary decisions as to where boundaries between groups lie. In the main text we use the term "functional types" to emphasize the functional axes differentiating species, rather than their specific groupings. Attention is now being directed towards alternative methods of quantifying both the diversity of functional traits of organisms and their effects on ecosystem properties (e.g., Grime et al. 1997b, Walker et al. 1999, Lavorel and Garnier 2001, Petchey 2002).

2) Traits that determine how a species responds to a disturbance or change in environment (functional response traits) may differ from those that determine how that species affects ecosystem properties (functional effect traits; Lavorel et al. 1997, Landsberg 1999, Walker et al. 1999, Lavorel and Garnier 2002). Recent studies on biodiversity/ ecosystem functioning have focused primarily on functional effect traits (Hooper and Vitousek 1997, Tilman et al. $1997 a$, Hooper and Vitousek 1998, Emmerson et al. 2001). Studies of how species distributions may change in response to climate change have focused primarily on functional response traits (e.g., Box 1996, Steffen 1996, Cramer 1997, Smith et al. 1997, Elmqvist et al. 2003). Response and effect traits may or may not be correlated with one another (Chapin et al. 1996a, Lavorel and Garnier 2002). Understanding links among functional response and effect traits remains a significant challenge, but is critical to understanding the dynamics of ecosystem functioning in a changing world (Lavorel and Garnier 2001, Hooper et al. 2002).

3) Functional types identified for a specific ecosystem property are not necessarily relevant to other properties. Defining types based on just a few traits known to affect many functions (such as specific leaf area, plant height, and seed mass; Westoby 1998, Grime 2001) may alleviate this problem, but whether such types yield insights into biodiversity/ecosystem functioning relationships within ecosystems remains unknown.

4) Is functional diversity correlated with species diversity in natural ecosystems? The answer to this question depends in part on mechanisms of community assembly (Fridley 2001, Hooper et al. 2002, Mouquet et al. 2002). The concepts of niche differentiation and limiting similarity imply that functional characteristics of coexisting organisms must differ at some level, which means that increasing species richness should lead to increasing functional diversity (Bazzaz 1987, Weiher and Keddy 1999a, Díaz and Cabido 2001, Schmid et al. 2002b). On the other hand, strong environmental filters could limit species composition to a relatively restricted range of functional characteristics (Pearson and Rosenberg 1978, Díaz et al. 1998, Weiher and Keddy 1999a, Díaz and Cabido 2001, Loreau et al. 2001, Lavorel and Garnier 2002), thereby limiting the degree of functional diversity capable of influencing different ecosystem properties (Grime 2001). Increasing species richness would then just lead to finer division of the available niche space rather than to greater functional diversity (Díaz and Cabido 2001, Enquist et al. 2002, Schmid et al. 2002b). Merging our understanding of ecosystem level controls with our understanding of community dynamics and assembly is an important focus of future study (Thompson et al. 2001).

richness, relative abundance, composition, presence/ absence of key species) can have different effects on ecosystem properties. We are explicit in our use of terminology in this paper, referring, for example, to "species richness" when discussing numbers of species, "diversity" when discussing more general attributes including differences in relative abundance and composition, and "biodiversity" only when the broadest scope of the term is warranted. In this paper, we focus mostly on changes in richness and composition at the species and functional type levels, not because they are always the most important, but because that is where most research has concentrated. Effects of genetic and functional diversity within species, inter- actions among species, and ecosystem diversity across landscapes are areas that deserve greater attention.

The total suite of functional traits in a community is one of the main determinants of ecosystem properties (Chapin et al. 1997, Chapin et al. 2000). We therefore discuss the effects of biodiversity with respect to the functional traits of the species involved (see Box 1 and Section I.C., below). We do so in the context of gain or loss of species from a given site or ecosystem, rather than in terms of cross-system comparisons of diversity where other environmental variables are also changing-though merging these perspectives begs for further study (see Sections I.C. and II.C., below). The number of species alone may not be the best predictor

(a) 
of ecosystem properties, and the relationship between species or taxonomic richness and functional diversity in natural ecosystems is still being explored (Díaz and Cabido 2001, Enquist et al. 2002, Hooper et al. 2002, Petchey 2002, Schmid et al. 2002 b, Tilman et al. 2002; see also Box 1 and Section II.C.2).

Ecosystem functioning is also a broad term that encompasses a variety of phenomena, including ecosystem properties, ecosystem goods, and ecosystem services (Christensen et al. 1996), although some researchers use the term "ecosystem functioning" as synonymous with ecosystem properties alone, exclusive of ecosystem goods and services. Ecosystem properties include both sizes of compartments (e.g., pools of materials such as carbon or organic matter) and rates of processes (e.g., fluxes of materials and energy among compartments). Ecosystem goods are those ecosystem properties that have direct market value. They include food, construction materials, medicines, wild types for domestic plant and animal breeding, genes for gene products in biotechnology, tourism, and recreation. Ecosystem services are those properties of ecosystems that either directly or indirectly benefit human endeavors, such as maintaining hydrologic cycles, regulating climate, cleansing air and water, maintaining atmospheric composition, pollination, soil genesis, and storing and cycling of nutrients (Christensen et al. 1996, Daily 1997). Ecosystem properties vary among ecosystems, but levels, rates, or amounts of variability of these properties are not inherently "good" or "bad." This is in contrast to ecosystem goods and services, to which humans attach value (although in some cases, the distinction between properties and services is not clear-cut). We refer to "ecosystem properties" to summarize the various pools and fluxes and to "ecosystem goods and services" only when referring to the subset of functioning of utilitarian value to humans.

When discussing effects of biodiversity on ecosystem functioning it is important to be specific about which components of biodiversity are affecting which components of functioning. Measures of process rates and pool sizes include both levels (e.g., average rates or sizes) and variation (amount of fluctuation). Variation in ecosystem properties can result from fluctuations in the environment from year to year, directional changes in conditions, abiotic disturbance, or biotic disturbance. There is no a priori reason to expect that different ecosystem properties have a single pattern of response to changes in different components of biodiversity, or that change in either direction is inherently "good" or "bad."

Sustainability refers to the capacity for a given ecosystem service to persist at a given level for a long period of time (Lubchenco et al. 1991, Valiela et al. 2000). While sustainability has been discussed widely, very few experiments have addressed it directly, in part because of the complexities involved. Because many ecosystem properties fluctuate naturally over time, the difficult task is to determine the bounds of natural fluctuations to better understand whether human-induced fluctuations are outside these natural ranges of variability and therefore present a new threat to sustainability of ecosystem services (Chapin et al. 1996c).

\section{Effects of diversity in the context of other ecosystem factors}

Many factors influence the magnitude and stability of ecosystem properties, including climate, geography, and soil or sediment type. These abiotic controls interact with functional traits of organisms to control ecosystem properties (Fig. 1; Chapin et al. 1997, 2000, 2002, Lavorel and Garnier 2002). The last half-century of ecosystem ecology research has yielded large amounts of information about how organismal traits influence ecosystem properties in both terrestrial and aquatic ecosystems, and about trade-offs and linkages of these traits in individual organisms (plant effects on soil properties, Muller 1884, Jenny 1941, 1980, Van Cleve et al. 1991; species' effects on ecosystem properties, Chapin et al. 1986, 2002, Vitousek 1986, 1990, Hobbie 1992, Jones and Lawton 1995, Smith et al. 1997; food webs, Carpenter et al. 1987, Carpenter and Kitchell 1993, de Ruiter et al. 1994, 1995, Elser et al. 1996, Schindler et al. 1997; trade-offs in plant traits, Grime 1979, Chapin 1980, Berendse et al. 1987, Grime et al. 1988, Tilman 1988, Aerts et al. 1990, Berendse and Elberse 1990, Chapin et al. 1993, Díaz et al. 1999, to name just a few). Ecosystem ecologists have traditionally focused on the functional traits of the most dominant organisms (those that are most abundant or have the greatest biomass within each trophic level) because they are the most obvious biotic factors regulating ecosystem properties (Grime 1998) (Box 1). Of course, certain species, although relatively rare or of low total biomass, can also have large effects (see review of keystone species in Power et al. 1996). In the context of species extinctions and invasions, understanding the effects of diversity adds another dimension to controls over ecosystem properties in diverse natural ecosystems (Kennedy et al. 2002). That is, under what circumstances do the traits of more than just one dominant species have a large influence on properties? When might species interactions be important? How many species are involved in particular community or ecosystem functions? Which species play significant roles and which do not? These questions have been studied to some extent in agriculture and agroforestry in the context of intercropping, although the levels of diversity examined are usually low relative to those in 


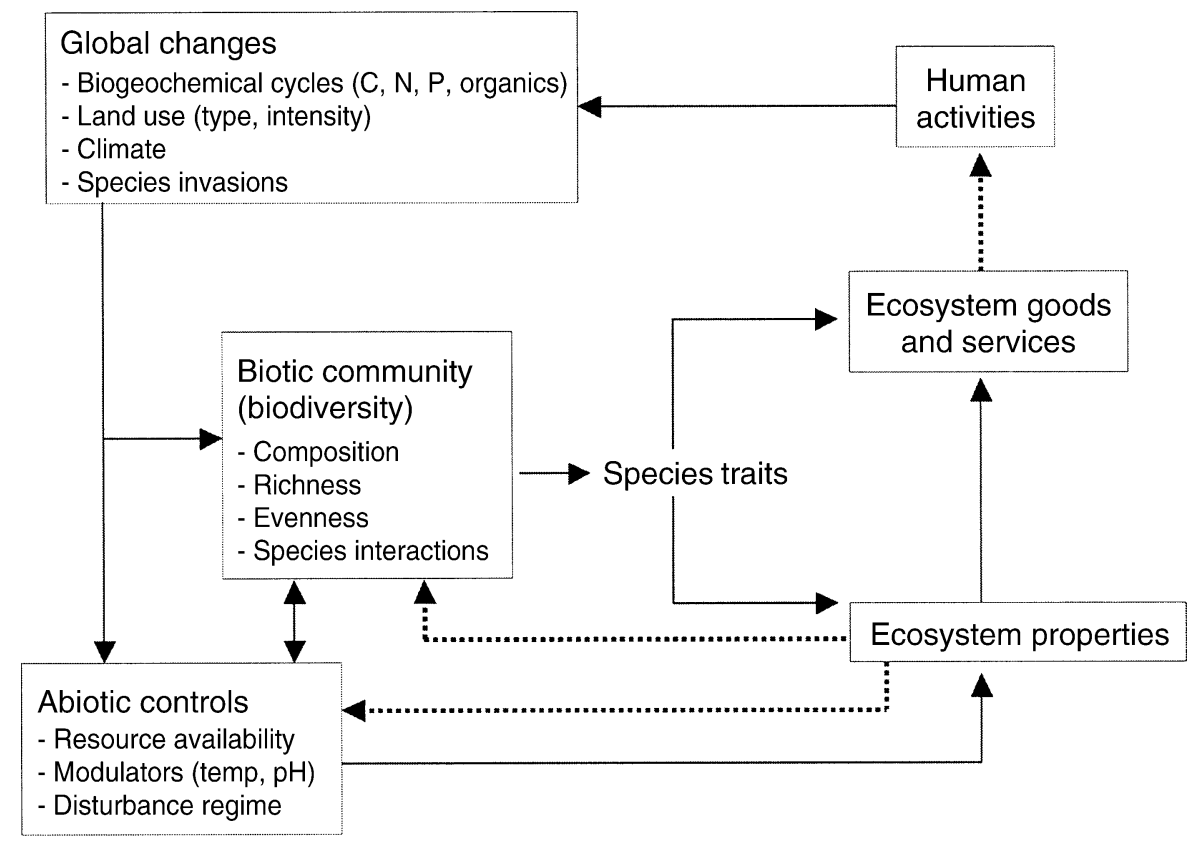

FIG. 1. Feedbacks between human activities, global changes, and biotic and abiotic controls on ecosystem properties. A number of human activities are now sufficiently widespread that their ecological effects have reached global proportions. These ecological effects alter both the biotic community and abiotic interactive controls on ecosystem properties. Some of the abiotic controls could also be considered ecosystem properties of interest. "Modulators" are abiotic conditions that influence process rates (e.g., temperature and $\mathrm{pH}$ ) but are not directly consumed in the process, in contrast to resources (Chapin et al. 2002). Various of aspects of the biotic community influence the range and proportion of species traits. These traits can further alter the abiotic controls, directly affect ecosystem properties, or directly affect ecosystem goods and services. Changes in ecosystem properties can feed back to further alter the biotic community either directly or via further alterations in abiotic controls (dotted lines). Feedbacks from altered goods and services can lead to modification of human activities, as evidenced in a variety of responses to environmental problems. A critical question is whether the rates and magnitudes of these human changes will be sufficient to offset some of the original adverse ecological effects. This figure is modified from Chapin et al. (2000).

natural ecosystems (Trenbath 1974, 1999, Vandermeer 1990, Swift and Anderson 1993).

Changes in biota can have greater effects on ecosystem properties than changes in abiotic conditions (e.g., Van Cleve et al. 1991, Chapin et al. 2000). Impacts of invasions, for example, clearly demonstrate that a single species or functional group can strongly influence ecosystem properties (e.g., Mooney and Drake 1986, Vitousek 1986, Griffin et al. 1989, Vitousek and Walker 1989, D'Antonio and Vitousek 1992, Alban and Berry 1994, Gordon 1998, Levine et al. 2003). On the other hand, cross-system comparisons suggest that abiotic conditions, disturbance regime, and functional traits of dominant plant species have a greater effect on many ecosystem properties than does plant species richness (e.g., Wardle et al. 1997b, 2003, Loreau 1998a, Enquist and Niklas 2001). Modifications of species diversity and composition result from a variety of environmental changes, including changes in land use, nutrient availability and cycling, atmospheric composition, climate, the introduction of exotic spe- cies, and overexploitation by humans (Fig. 1). Different types of environmental change are hypothesized to lead to different patterns of biodiversity modification for different types of species and ecosystems (Sala et al. 2000). An important goal of future research is to improve our understanding of the relative importance of the changes in different abiotic and biotic controls over specific ecosystem properties in different ecosystems. Success in answering these questions requires a closer coupling of recent theoretical and experimental approaches with the substantial information available from physiological, population, community, and ecosystem ecology on which sets of traits influence species distributions, species interactions, and particular aspects of ecosystem functioning (Box 1).

\section{EfFects of Diversity on Ecosystem PROPERTIES}

\section{A. Magnitudes of ecosystem properties}

1. Theory and hypotheses.-Magnitudes of ecosystem processes or sizes of pools could respond to chang- 
es in species or functional diversity in several ways. The patterns depend on the degree of dominance of the species lost or gained, the strength of their interactions with other species, the order in which species are lost, the functional traits of both the species lost and those remaining, and the relative amount of biotic and abiotic control over process rates (Vitousek and Hooper 1993, Lawton 1994, Naeem et al. 1995, Sala et al. 1996, Naeem 1998). Indeed, more than 50 potential response patterns have been proposed (Loreau 1998a, Naeem $2002 b$ ). Here we focus on the most common ones and highlight several key points.

(a) Diversity might have no effect: changing relative abundance or species richness might not change process rates or pool sizes. - Lack of response could occur for several reasons, such as primary control by abiotic factors, dominance of ecosystem effects by a single species that was not removed, or strong overlap of resource use by different species (Vitousek and Hooper 1993, Cardinale et al. 2000, Petchey 2000, Fridley 2001).

(b) Increases in ecosystem functioning with increasing diversity could arise from two primary mechanisms.-

(i) First, only one or a few species might have a large effect on any given ecosystem property. Increasing species richness increases the likelihood that those key species would be present (Aarssen 1997, Huston 1997, Tilman et al. 1997b, Loreau 2000). This is known as the sampling effect or the selection probability effect. As originally formulated, the sampling effect hypothesis assumes that competitive success and high productivity are positively associated at the species level (Fig. 2A; Hector et al. 2000b, Troumbis et al. 2000, Tilman 2001). Predicting the species that will have the greatest influence on properties in complex mixtures is not always straightforward, however. In some environments, competitive success may be more strongly linked to storage allocation, interference competition, or other strategies that do not maximize growth rates (e.g., Grime 1979, Haggar and Ewel 1995, Grime 2001, Hooper and Dukes 2004), in which case sampling effects could actually lead to lower average productivity (Hector et al. 2000b, Troumbis et al. 2000, Tilman 2001). For other properties, relatively rare species could have dominant effects on ecosystem functioning, despite having low total productivity, biomass, or abundance (e.g., resistance to invasions; Lyons and Schwartz 2001). Generally, we need to understand which traits determine competitive success and potential for dominance over ecosystem properties, particularly for processes other than biomass production.

(ii) Second, species or functional richness could increase ecosystem properties through positive interactions among species. Complementarity and facilitation
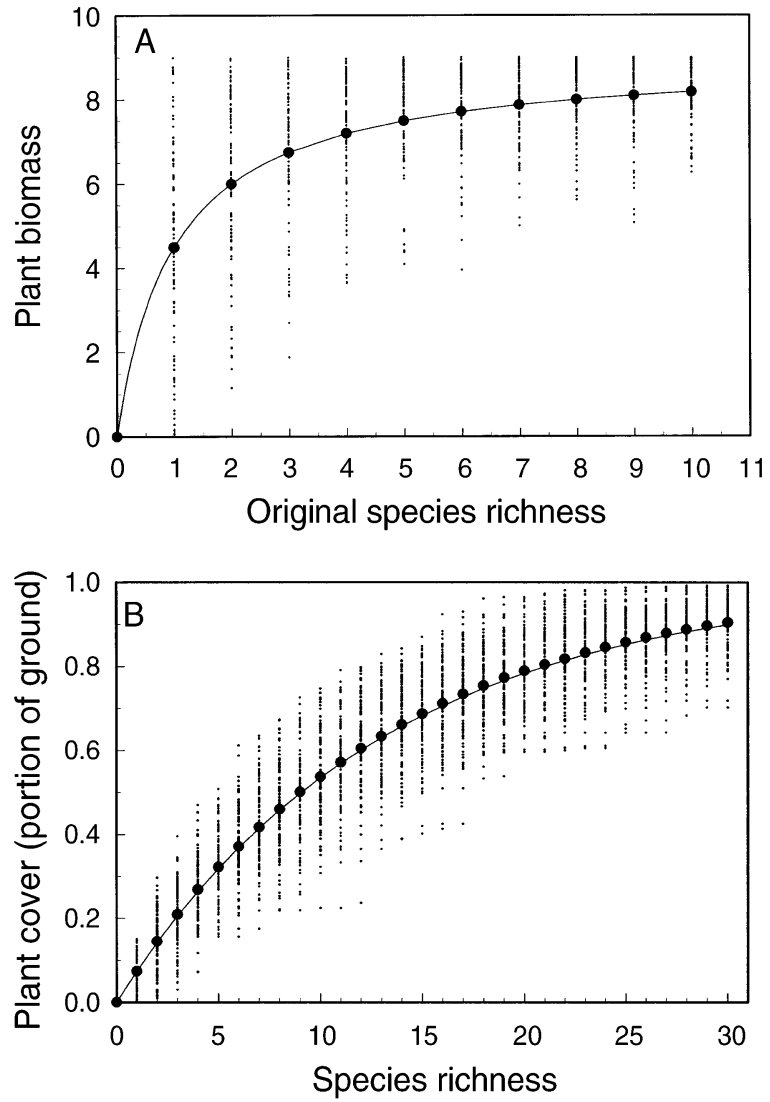

FIG. 2. Theoretical examples of how changing species diversity could affect ecosystem properties. Lines show average response, and points show individual treatments. (A) Selection effect for a dominant species: average ecosystem properties increase with increasing species richness, but maximal response is also achievable with particular combinations even at low diversity. The increase in average response results from the greater probability of including the most effective species as species richness increases. The figure illustrates results for productivity as change in aboveground biomass. (B) Complementarity and/or positive interactions among species, illustrated for plant cover as an index of aboveground primary productivity in a system with all new aboveground growth each year. Once there is at least one of each different type of species or functional type, effects of increasing species richness on ecosystem properties should begin to saturate; adding more species at that point would have progressively less effect on process rates (Tilman et al. 1997b, Loreau 2000). Where the relationship saturates depends on the degree of niche overlap among species (Petchey 2000, Schwartz et al. 2000). The figures are from Tilman (1997b).

are the two primary mechanisms leading to the phenomenon of overyielding, in which plant production in mixtures exceeds expectations based on monoculture yields (Trenbath 1974, Harper 1977, Ewel 1986, Vandermeer 1989, Loreau 1998b, but see also Petchey 2003). Complementarity results from reduced interspe- 
cific competition through niche partitioning. If species use different resources, or the same resources but at different times or different points in space, more of the total available resources are expected to be used by the community (Trenbath 1974, Harper 1977, Ewel 1986, Vandermeer 1989). If those resources limit growth, then increasing functional richness should lead to greater total productivity and decreased loss of resources from the ecosystem. Facilitative interactions among species could also lead to increases in ecosystem pools or process rates as species or functional richness increase. Such facilitation could occur if certain species alleviate harsh environmental conditions or provide a critical resource for other species (Fowler 1986, Bertness and Callaway 1994, Chapin et al. 1994, Berkowitz et al. 1995, Mulder et al. 2001, Bruno et al. 2003).

(c) A saturating response of ecosystem properties to increasing species richness is the most commonly hypothesized pattern.-Complementarity, facilitation, and sampling effects for high productivity (or other properties) are all expected to show a similar saturating average response as diversity increases (Fig. 2). Distinguishing among these different hypotheses requires comparisons of individual species' performances in monocultures and mixtures (Trenbath 1974, Tilman et al. 1997b, Hector 1998, Hooper 1998, Loreau 1998b, Mikola and Setälä 1998b, Norberg 2000, Loreau and Hector 2001, Drake 2003) grown close to natural densities to avoid yield dependence on density at low density (Connolly 1986, Cousens and O'Neill 1993) and difficulties with establishment at high densities (Harper 1977). Loss of complementarity or facilitation will be most likely to affect ecosystem properties after species loss has resulted in highly impoverished communities. At the same time, variability in ecosystem response to species loss may be expected to increase as communities become more biotically impoverished because of “idiosyncratic" effects (sensu Lawton 1994, Naeem et al. 1995) determined by the traits of the particular species going extinct or remaining in the community (Petchey 2000; see Section II.B.).

(d) Complementarity and selection or sampling effects are not necessarily mutually exclusive.-There can be a continuum of diversity effects, ranging from the probability of sampling one dominant species to the probability of selecting several complementary species (Huston et al. 2000, Loreau 2000). More diverse communities are more likely to include a dominant species or a particular combination of species that are complementary. Furthermore, differences in resource allocation, resource use efficiency, and the amount of difference in functional traits among species could modify both complementary and sampling effects (Haggar and Ewel 1995, Huston 1997, Tilman et al. 1997b, Nijs and Impens 2000, Nijs and Roy 2000).

(e) Ecologists disagree over whether sampling effects are relevant to natural ecosystems.- Some ecologists argue that they are artifacts of certain experimental designs because of their dependence upon an assumption that communities are random assemblages of species from the total species pool (Huston 1997, Wardle 1999), while communities are arguably not random assemblages of species (Connell and Slatyer 1977, Weiher and Keddy 1999b). Others assert that they are simply an alternative mechanism by which species richness might influence ecosystem properties in natural communities, pointing out that there are many stochastic factors that can influence community composition (Tilman et al. 1997b, Loreau 2000, Mouquet et al. 2002). Resolving disagreements about the relevance of sampling effects to natural systems will require a better understanding of the links between ecosystem properties and the interactions between deterministic (competition, trait/environment linkages) and stochastic (disturbance and colonization) processes that determine community composition.

(f) Adding multiple trophic levels is expected to lead to more complex responses in ecosystem properties than in single-trophic-level models.-Most theoretical research has focused on within-trophic group diversity, such as plant diversity. Relatively few theoretical studies examine effects of species richness on ecosystem properties in multi-trophic systems (Johnson 2000, Loreau 2001, Holt and Loreau 2002, Thébault and Loreau 2003). These studies suggest variable responses of primary and secondary productivity to changing species richness in multiple trophic levels, depending on a variety of factors, such as the degree to which the system is closed to immigration, emigration, and allochthonous inputs, the degree of top-down vs. bottom-up control, food web connectivity, and the trophic level and functional characteristics of the species gained or lost.

2. Experiments and observation.-Much of the experimental work on the effects of plant diversity on ecosystem properties has focused on primary productivity and ecosystem nutrient retention, although a growing number of studies have considered decomposition and nutrient dynamics as well. Intercropping and agroforestry research is highly relevant to understanding diversity effects on ecosystem properties (e.g., Trenbath 1974, Harper 1977, Ewel 1986, Vandermeer 1990, Loreau 1998b, Fridley 2001, Hector et al. 2002), although most such studies deal with only two to three species, rather than the greater diversity characteristic of natural ecosystems (Swift and Anderson 1993). Recent ecological experiments on the response of productivity to changing species richness in relatively di- 
verse communities have focused on broader theoretical questions, rather than specific management goals, and sought to investigate patterns of ecosystem response that might occur at higher levels of diversity. Such questions include: What is the general shape of the response of productivity and other properties to increasing numbers of species, ranging from one species up to the levels of diversity characteristic of natural communities? If the response saturates, at what level of richness does this occur? What are the relative roles of functional diversity and species diversity in affecting that response? Many studies explicitly vary plant species richness in experimental communities in grasslands because they are easy ecosystems to manipulate and aboveground net primary productivity is relatively easy to approximate because all aboveground biomass is generally accrued during a single year. Still, these measurements may underestimate productivity if they do not take into account intra-annual turnover (Scurlock et al. 2002). Recently, evidence for properties other than production and from ecosystems other than grasslands has begun to accumulate as well, resulting in the following generalizations:

(a) Differences in species composition exert a strong effect on productivity and other ecosystem properties.-Ecosystem response to extinction or invasion in the real world will be determined at least as much by which species and functional traits are lost and remain behind as by how many species are lost. As stated above (Section I.C.), research in ecosystem ecology over the past half century has demonstrated that organismal functional traits are one of the key controls on ecosystem properties. Recent studies on the effects of diversity on ecosystem functioning in both terrestrial and aquatic ecosystems support those findings: Most observe large variability in ecosystem properties within levels of species or functional richness that can be attributed at least in part to differences in species or functional composition (Fig. 3; Naeem et al. 1995, Tilman et al. 1996, 1997a, Haggar and Ewel 1997, Hooper and Vitousek 1997, Hooper 1998, Symstad et al. 1998, Hector et al. 1999, Norberg 1999, Wardle et al. 1999, Spehn et al. 2000, Van der Putten et al. 2000, Lepš et al. 2001, Hector 2002). These experiments suggest that, as predictors of ecosystem properties, community composition (knowing which species or functional types are present) is at least as important as species or functional richness alone (knowing how many species or functional types are present).

Soil processes in particular appear to be primarily influenced by the functional characteristics of dominant species rather than by the number of species present (but see Zak et al. 2003). Decomposition, soil organic matter dynamics, nutrient uptake by soil micro-organisms, and nutrient retention, for example, are more strongly influenced by differences in functional traits (e.g., leaf chemistry, phenology) of the dominant plant species than by the diversity of plant species (Hooper and Vitousek 1997, 1998, Wardle et al. 1997a, b, 1999, Bardgett and Shine 1999, Hector et al. 2000a, Korthals et al. 2001). Less is known about how the diversity of soil organisms affects rates of decomposition and nutrient cycling (Balser et al. 2002, Mikola et al. 2002). Composition and diversity of mycorrhizal fungi influence plant community composition and productivity (van der Heijden et al. 1998, 1999, but see Wardle 1999), as well as productivity of individual plants, but effects can be positive, negative, or neutral depending on soil fertility and the plant species involved (Jonsson et al. 2001). Litter decomposition rates can depend on the composition of the soil faunal community, which in turn is influenced by the plant species present (Chapman et al. 1988, Blair et al. 1990, Williams 1994, but see also Andrén et al. 1995). Experimental studies based on synthesized soil food webs point to food web composition, rather than the diversity of organisms within trophic levels, in driving decomposition properties (Mikola and Setälä 1998a) and plant productivity (Laakso and Setälä 1999).

(b) Patterns of response to experimental manipulations of species richness vary for different processes, different ecosystems, and even different compartments within ecosystems.-In some experiments with herbaceous plants, average plant productivity increases, and levels of available soil nutrients often decrease, with increasing plant species or functional richness, at least within the range of species richness tested and over the relatively short duration of many experiments (Fig. 3; Tilman et al. 1996, 1997a, 2001, 2002, Hector et al. 1999, Loreau and Hector 2001, Niklaus et al. 2001a, Fridley 2003). In these experiments, the responses to changing diversity are strongest at low levels of species richness and generally saturate at 5-10 species (but see Section II.B., below, for more on levels of saturation). However, increases in process rates with increasing species richness do not always occur. In some experiments with longer-lived perennials, ecosystem responses (NPP, nutrient retention, nutrient use efficiency) are maximized with only one or two species (e.g., Ewel et al. 1991, Haggar and Ewel 1997, Hiremath and Ewel 2001; Fig. $3)$. Idiosyncratic patterns sometimes result from strong effects of species composition, in which the functional traits of particular species overwhelm responses to species richness (Hooper and Vitousek 1997, Symstad et al. 1998, Kenkel et al. 2000, Troumbis et al. 2000, Mulder et al. 2001). These patterns, seen under experimental conditions, may or may not reflect actual patterns seen for a particular ecosystem under a particular scenario of species loss or invasion, which will depend not only on the functional effect traits of the species 

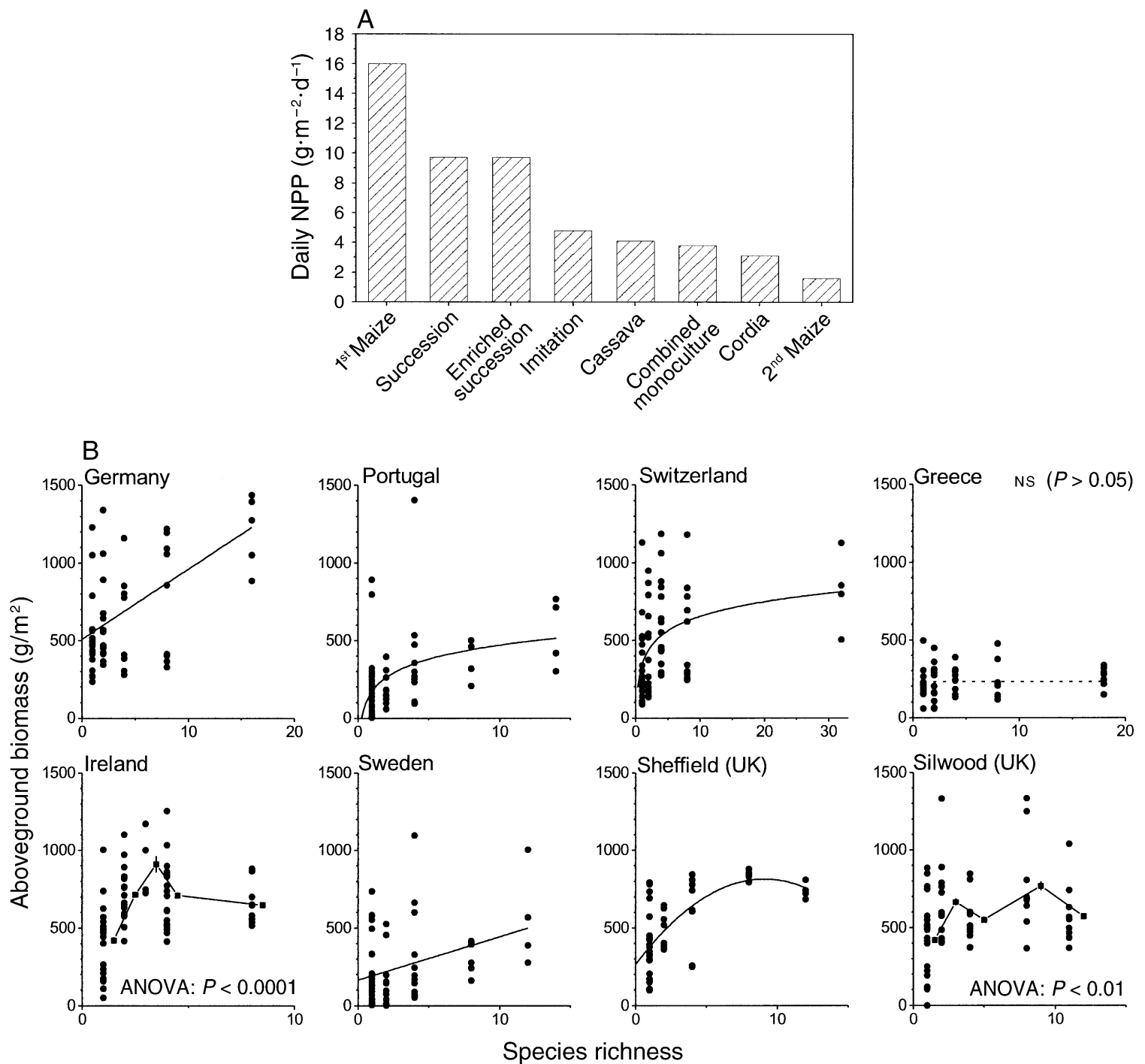

Species richness

FIG. 3. Variation in effects of plant species richness and composition on plant productivity. (A) Experiments in the tropics. Treatments ran for five years and included four monocultures (two rotations [1st and 2nd] of maize [Zea mays], one rotation of cassava [Manihot esculenta], and one rotation of a tree, Cordia alliodora); a diverse ( $>100$ plant species) natural succession following clearing and burning of original vegetation; a species-enriched $(\sim 120$ species $)$ version of natural succession; and an imitation of succession that mimicked the plant life forms in the natural succession treatment, but with different species. Monocultures were timed to coincide with growth phases of natural succession: maize during the initial herbaceous stage, cassava during the shrub-dominated stage, and $C$. alliodora during the tree-dominated stage. Note that the maize monoculture had both the highest and lowest overall productivity, and that the productivity of the successional vegetation was not increased by further increases in species richness. This figure is modified from Ewel (1999). (B) The pan-European BIODEPTH experiment. At several sites, plant productivity increased with increasing species richness, although the pattern of response varied in individual location analyses. Five of the sites had either non-saturating or saturating patterns (on a linear scale). At two sites significant differences across different levels of diversity (ANOVA) provided a better model than a linear regression. One site (Greece, dotted line) showed no significant relationship between aboveground plant productivity and species richness. Even where there are strong trends in the diversity effect, there is also variation within levels of richness resulting in part from differences in composition. Points are individual plot biomass values, and lines are regression curves or join diversity level means (squares for Ireland and Silwood). The figure is after Hector et al. (1999). 
involved, but also on the traits that determine how species respond to changes in environmental conditions (i.e., both effect and response traits, Box 1 and Section II.B.2; Symstad and Tilman 2001, Lavorel and Garnier 2002). Understanding the causes of variability in response patterns for different ecosystem types and different environmental conditions remains an important question.

(c) Both sampling effects and positive species interactions have been observed in experiments, and multiple mechanisms can operate simultaneously or sequentially.-Resolving the mechanisms by which experimental manipulation of species richness leads to increased productivity or other processes has led to substantial debate (see Section II.A.1. Theory and hypotheses, above; Aarssen 1997, Garnier et al. 1997, Huston 1997, van der Heijden et al. 1999, Wardle 1999, Hector et al. 2000b, Huston et al. 2000). Many experiments were designed to test general patterns, rather than to test mechanisms for those patterns. Those that do test explicitly for mechanism clearly indicate that alternatives are often not mutually exclusive. Both positive interactions among species (complementarity and/ or facilitation) and selection for highly productive species occurred in synthetic grassland communities in Europe (Loreau and Hector 2001) and Minnesota (Tilman et al. 1996, 2001, Reich et al. 2001). ${ }^{17}$ Positive interactions involving at least two species are occurring, but whether this results from facilitation or complementarity and how many species are involved is unclear (Huston and McBride 2002, Tilman et al. 2002, Wardle 2002). Evenness of the plant community also could lead to increased productivity with increasing species richness (e.g., Nijs and Roy 2000, Schwartz et al. 2000, Wilsey and Potvin 2000, Polley et al. 2003). Effects of plant diversity on soil nutrients can be mediated simultaneously by direct plant uptake and by effects of plants on soil microbial dynamics (Hooper and Vitousek 1997, 1998, Niklaus et al. 2001a).

Several questions remain unresolved. For example, what functional traits of species lead to dominance and how do traits for dominance overlap with functional effect traits (Weiher and Keddy 1999b, Suding et al. 2003)? Several recent experiments have shown that the

\footnotetext{
${ }^{17}$ Note that the use of the term "selection" in the Additive Partitioning Equation (APE; Loreau and Hector 2001) is different from the "sampling effect" or "selection probability effect" (Huston 1997, Tilman et al. 1997b). The "selection effect" of the APE refers to the tendency for species interactions in mixtures to "select for" or favor species with particular traits (e.g., high productivity in monoculture), whereas sampling effects refer to the higher probability of including such species in randomly selected mixtures as the species richness of experimental treatments increases. Both of these aspects must hold for sampling effects to be the primary driver of ecosystem properties.
}

species with the greatest productivity in monoculture is not necessarily the species that dominates production in mixtures (Hooper and Vitousek 1997, Troumbis et al. 2000, Engelhardt and Ritchie 2001, Špaèková and Lepš 2001, Hector et al. 2002, Hooper and Dukes 2004), contrary to some early formulations of the sampling effect hypothesis (Huston 1997, Tilman et al. 1997b).

To further understand diversity effects on ecosystem properties, future experiments need to include explicit experimental controls (e.g., growing all species in monoculture as well as in mixture, Hector 1998, Hooper 1998, Loreau 1998b, Engelhardt and Ritchie 2002, Fridley 2003, Hooper and Dukes 2004; or having matrix species alone at different densities, Haggar and Ewel 1997), or at the minimum, statistical controls (e.g., measurements of potential controlling variables) to help differentiate among mechanisms (Huston and McBride 2002, Schmid et al. 2002a). Optimally, growing all possible polycultures, as well as monocultures, would help distinguish sampling effects for small numbers of species, but this approach may not be experimentally tractable.

(d) The strength of positive interactions varies with both the functional characteristics of the species involved and the environmental context.-Extensive research over many decades in intercropping and agroforestry shows that the degree of complementarity or facilitation among crop or forestry species varies greatly (e.g., Vandermeer 1989, 1990, Ong and Black 1994, Haggar and Ewel 1997, Ong and Huxley 1997). Similar variation in the strength of positive interactions occurs in ecological experiments, such as those investigating competition (Harper 1977, Berendse 1982, 1983, Bazzaz 1987), and more recent experiments assessing complementarity and facilitation among terrestrial and aquatic plants (Hooper 1998, Dukes 2001b, Engelhardt and Ritchie 2002, Schmid et al. 2002b, Fridley 2003, Polley et al. 2003, van Ruijven and Berendse 2003, Hooper and Dukes 2004), and aquatic animals (Norberg 2000, Emmerson et al. 2001).

Complementarity and/or facilitation are usually greatest when species differ greatly in functional traits, whether in timing (Steiner 1982, Chesson et al. 2002, but see Stevens and Carson 2001), spatial distribution (Schenk and Jackson 2002), or type of resource demand (e.g., McKane et al. 2002). One of the most important forms of facilitation among plants occurs when at least one species has the ability to form a symbiotic association with nitrogen-fixing bacteria (Trenbath 1974, Cannell et al. 1992). Interactions between legumes and non-legumes are clearly one of the major functional mechanisms for the results of many grassland biodiversity experiments (e.g., Tilman et al. 1997a, 2002, Hector et al. 1999, Mulder et al. 2002, Spehn et al. 
2002). However, they are not necessarily the whole story. Effects of additional species can be detected in some of these studies (Loreau and Hector 2001, Tilman et al. 2001, 2002) and overyielding has been found in many mixtures omitting legumes (e.g., Trenbath 1974, Haggar and Ewel 1997, Jolliffe 1997, van Ruijven and Berendse 2003, Hooper and Dukes 2004).

Environmental context, both abiotic and biotic, can add variability to the strength of positive interactions (Cardinale et al. 2000, Emmerson et al. 2001, Fridley 2001, Hooper and Dukes 2004). In intercropping studies, much effort goes into determining the appropriate conditions (e.g., spacing of individuals, timing of plantings, soil conditions) to maximize total yields. In natural systems, facilitation is most common in unproductive or stressful environments (Bertness and Callaway 1994, Callaway et al. 2002, Bruno et al. 2003). On the other hand, increasing resource availability may allow for stronger complementarity. Positive shortterm effects of species richness on aboveground productivity are often greater with higher resource availability, such as $\mathrm{CO}_{2}$ or fertilizer enrichment (Stocker et al. 1999, Niklaus et al. 2001b, Reich et al. 2001, Fridley 2002, 2003, He et al. 2002), although evidence suggests both complementarity and sampling effects as the underlying mechanisms in different experiments. Such results need to be reconciled with the well-known phenomenon of decreasing plant diversity with increasing fertilization (e.g., Grime 1973a, 1979, Tilman 1987). For example, how do predictions for positive interactions relate to predictions from the humpbacked model of species diversity (see Sections I.C. and II.C.)? The influence of environmental variation and differences in species' functional traits on complementarity and facilitation in complex natural and seminatural communities deserves more empirical study.

(e) Higher species richness within sites tends to decrease invasion by exotic species, though cross-site comparisons often show positive correlations between richness and invasibility.-At the landscape-scale, variability in factors such as soil fertility, propagule input, and disturbance regimes tend to outweigh effects of species richness on invader success, often leading to positive correlations between invader success and species richness when making comparisons across different sites (Planty-Tabacchi et al. 1996, Levine and D’Antonio 1999, Stohlgren et al. 1999, Levine 2000), although counterexamples exist (Gido and Brown 1999, Sax and Brown 2000). However, when making comparisons under common conditions, increasing species richness generally decreases the success of invasives (McGrady-Steed et al. 1997, Tilman 1997a, 1999, Knops et al. 1999, Stachowicz et al. 1999, Levine 2000, Naeem et al. 2000b, Prieur-Richard and Lavorel 2000, Symstad 2000, Dukes 2001a, Hector et al. 2001a, Ly- ons and Schwartz 2001, Kennedy et al. 2002, Fargione et al. 2003). A decrease in invasibility with increasing species richness within sites could occur by a variety of mechanisms, such as a greater probability of including species with traits similar to potential invaders, by more species utilizing a greater proportion of the potentially available resources (Elton 1958, Tilman 1999), a greater probability of including strongly competitive species (Wardle 2001a), or the greater likelihood of including biotic controls of a prospective invader. Conversely, increasing species richness can increase invasibility within sites if these additions result in increased resource availability, as in the case of nitrogen-fixers (Prieur-Richard et al. 2002a), or increased opportunities for recruitment through disturbance (e.g., D'Antonio 2000). Integrating results from field surveys with results from within-site experimental manipulations and mathematical models is important for both theoretical understanding and for broad-scale management of exotic species' invasions (Levine and D’Antonio 1999, Levine 2000, Shea and Chesson 2002).

(f) Varying diversity and composition of heterotrophs can lead to more idiosyncratic behavior than varying diversity of primary producers alone.-As multitrophic diversity increases, average process rates could increase, decrease, stay the same, or follow more complex nonlinear patterns (e.g., Carpenter and Kitchell 1993, Schindler et al. 1997, Klironomos et al. 2000, Cardinale et al. 2002, Mikola et al. 2002, Paine 2002, Raffaelli et al. 2002; see also Section II.A.1(f), above). Such complex patterns (e.g., Thébault and Loreau 2003) might explain why experimental results obtained with a small number of diversity levels appear somewhat variable. Many aquatic and terrestrial experiments have manipulated the abundance of one or a few consumer species (citations in previous sentences). A growing number of experiments have specifically manipulated diversity of more than one trophic level, although experimental difficulties in doing so restrict many of these experiments to micro- or mesocosms (e.g., Naeem et al. 1994, 2000a, McGrady-Steed et al. 1997, Mikola and Setälä 1998a, Laakso and Setälä 1999, Mulder et al. 1999, Petchey et al. 1999, Wardle et al. 2000a, Downing and Leibold 2002, plus above references).

The major point that emerges is that the functional characteristics of single species, whether native or not, can have a large impact on both community structure and ecosystem functioning. Changes in composition and diversity at one trophic level can influence diversity either positively or negatively in other trophic levels by a variety of mechanisms (Hunter and Price 1992, Strong 1992, Wardle et al. 1999, Duffy and Hay 2000, Hooper et al. 2000, Klironomos et al. 2000, Norberg 
2000, Stephan et al. 2000). Subtle differences in species interactions and environmental conditions can make the resulting effects on ecosystem properties difficult to predict (Berlow 1999, Wolters et al. 2000, Duffy et al. 2001, Schmid et al. 2002b). However, understanding the functional relationships among species within and across trophic levels helps to explain some of the apparently idiosyncratic ecosystem behavior that results (de Ruiter et al. 1994, 1995, Hulot et al. 2000, Bradford et al. 2002). Greater experimental efforts at understanding multitrophic changes in diversity constitute a clear need for future research.

\section{B. Variability in ecosystem properties}

1. Theory and hypotheses.-Ecologists hypothesize that ecosystem properties should be more stable in response to environmental fluctuations as diversity increases. Studies of the relationship between diversity and stability have a long tradition in ecology (MacArthur 1955, May 1974, Pimm 1984, McCann 2000), but findings have sometimes been clouded by inconsistent terminology. First, the distinction must be drawn between the stability of community composition and the stability of ecosystem process rates. In the former case, changing community composition is considered instability (May 1974); in the latter case, changing community composition is one mechanism that can help promote stability of ecosystem properties (McNaughton 1977, Tilman 1996, 1999, Lehman and Tilman 2000). In addition, "stability" in biotic communities is an umbrella term that refers to a large number of potential phenomena, including, but not limited to, resistance to disturbance, resilience to disturbance, temporal variability in response to fluctuating abiotic conditions, and spatial variability in response to differences in either abiotic conditions or the biotic community (May 1974, Pimm 1984, Holling 1986, McNaughton 1993, Peterson et al. 1998, Chesson 2000, Lehman and Tilman 2000, Cottingham et al. 2001, Chesson et al. 2002, Loreau et al. 2002a). Most theoretical work has focused on temporal variability, although some of the same principles may apply to other types of stability. Exploring the effects of species richness and composition on other dimensions of stability is a clear need for future research.

Theory about the relationship between species richness and stability of ecosystem processes has been developed in several forms, both via simple ecological reasoning and via mathematical models. Consensus on several points emerges from these different approaches.

(a) A diversity of species with different sensitivities to a suite of environmental conditions should lead to greater stability of ecosystem properties.-In this sense, redundancy of functional effect traits and diversity of functional response traits (see Box 1) act as insurance in carrying out ecological processes (MacArthur 1955, Elton 1958, Chapin and Shaver 1985, Walker 1992, Lawton and Brown 1993, Naeem 1998, Petchey et al. 1999, Trenbath 1999, Walker et al. 1999, Yachi and Loreau 1999, Hooper et al. 2002). If an ecosystem is subject to a variety of natural and humancaused environmental stresses or disturbances, then having a diversity of species that encompass a variety of functional response types ought to reduce the likelihood of loss of all species capable of performing particular ecological processes, as long as response traits are not the same as or closely linked to effect traits (Chapin et al. 1996a, Lavorel and Garnier 2002). This diversity of different functional response types also leads to asynchrony in species' demographic responses to environmental changes. Asynchrony results in compensation among species: As some species do worse, others do better because of different environmental tolerances or competitive release. In such cases, unstable individual populations stabilize properties of the ecosystem as a whole (McNaughton 1977, Tilman 1996, 1999, Hughes and Roughgarden 1998, Ives et al. 1999, Landsberg 1999, Walker et al. 1999, Lehman and Tilman 2000, Ernest and Brown 2001a). By similar reasoning, processes that are carried out by a relatively small number of species are hypothesized to be most sensitive to changes in diversity (Hooper et al. 1995), and loss of regional species richness is hypothesized to compromise recruitment and regeneration of potentially dominant species under changing environmental conditions (Grime 1998).

Several mathematical models generally agree with the hypotheses just described (see McCann 2000, Cottingham et al. 2001, Loreau et al. 2002a, for reviews). If species abundances are negatively correlated or vary randomly and independently from one another, then overall ecosystem properties are likely to vary less in more diverse communities than in species-poor communities (Fig. 4; Doak et al. 1998, Tilman et al. 1998). This statistical averaging is similar to diversified stock portfolios: The more companies in which one invests, the lower the risk of losing all of one's savings should one company collapse. The strength of the modeled effects of asynchrony depends on many parameters, including the degree of correlation among different species' responses (Doak et al. 1998, Tilman et al. 1998, Tilman 1999, Yachi and Loreau 1999, Lehman and Tilman 2000, Chesson et al. 2002), the evenness of distribution among species' abundances (Doak et al. 1998), and the extent to which the variability in abundance scales with the mean (Tilman 1999, Yachi and Loreau 1999, Cottingham et al. 2001).

(b) The numbers of species or genotypes necessary to maintain ecosystem properties increases with increasing spatial and temporal scales.-It follows from 

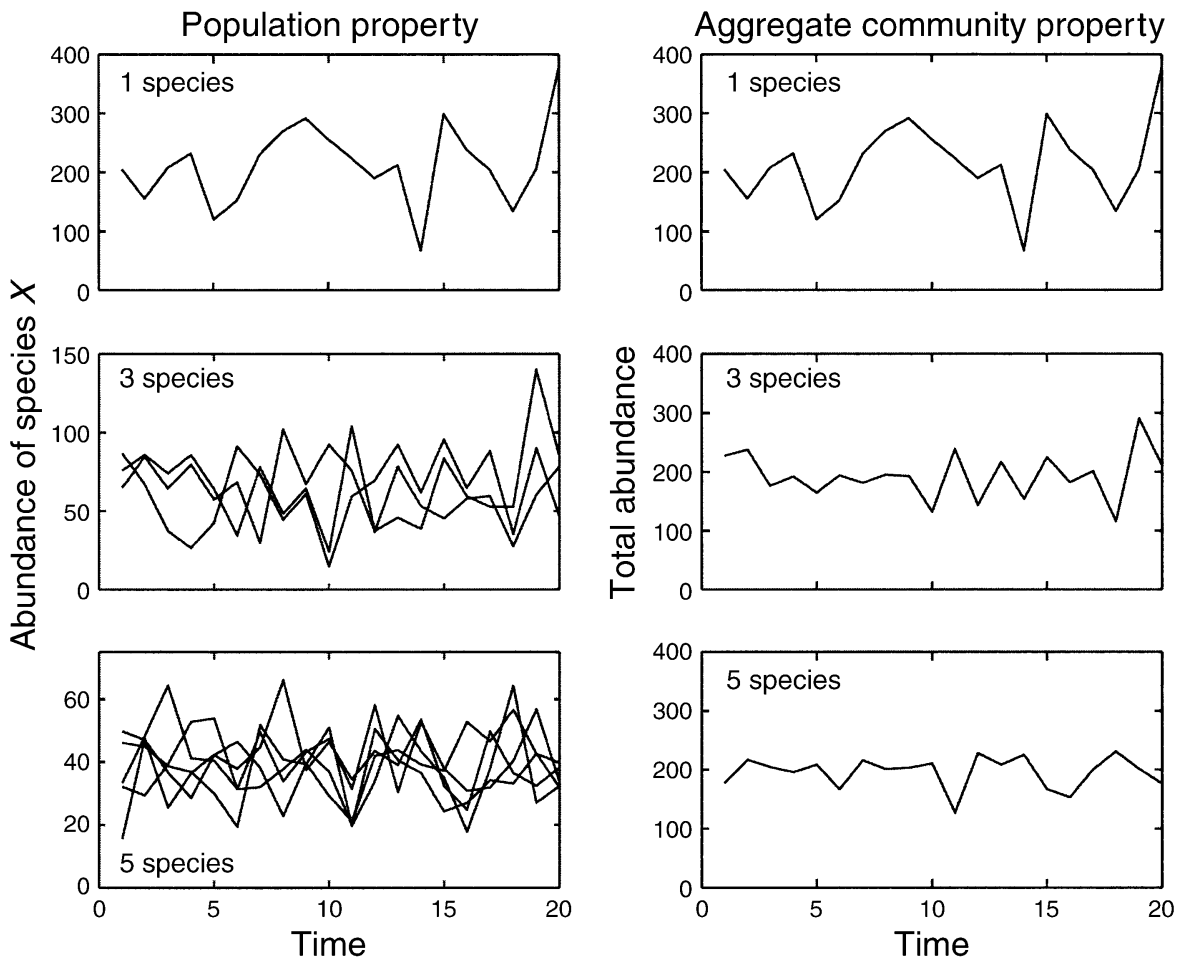

FIG. 4. Simulated stability of individual populations and a resulting community property (summed abundances of individual species) illustrating the portfolio effect of Doak et al. (1998). The model is from Tilman (1999); the figure is from Cottingham et al. (2001). The decrease in aggregate variability with increasing numbers of species results from the random fluctuations of the individual species. Underlying assumptions that contribute to the degree of dampening include equal abundance of all species and no correlation $(r=0)$ among species' temporal dynamics.

point 1 , above, that, while magnitudes of ecosystem properties may saturate at relatively low levels of species richness in small-scale, short-term experiments, more genetic diversity, either in terms of different species or genetic diversity within species, is necessary as a greater variety of biotic and abiotic conditions are encountered (Field 1995, Pacala and Deutschman 1995, Casperson and Pacala 2001, Chesson et al. 2002). This could have a variety of implications for the sustainability of ecosystem services in the long term (see Section III, below; Ewel 1986).

(c) The underlying assumptions of the mathematical models need further investigation and more experimental confirmation.-These assumptions include the degree of negative covariance, the relative abundances of species, the measures of stability used, and the amount of overyielding built into the models (Cottingham et al. 2001, Chesson et al. 2002). To that end, new or different models that encode these same assumptions do not necessarily lend more support to the diversity/ stability hypothesis; they are simply different mathematical configurations of the same thing. For example, several models have negative covariance, equal species abundances, or overyielding built in, either implicitly or explicitly (e.g., Lehman et al. 1975, Tilman 1999, Lehman and Tilman 2000). Increasing productivity with increasing species richness via overyielding leads to greater stability if the coefficient of variation (CV) or its inverse, $S$ (Tilman 1999) is used as the measure of stability, because of a higher mean productivity, not because of lower variance (Lehman and Tilman 2000). The strength of stabilization is likely to be maximal in such cases (Doak et al. 1998, but see also Yachi and Loreau 1999). Further exploration of the parameter space for all these variables is necessary before such models can be considered more proof that diversity stabilizes ecosystem processes.

Similarly, use of either CV or net variance as a measure of stability is well supported theoretically, but which measure is most relevant and the extent to which stability might be influenced may depend on the particular application and how variance scales with the mean (the " $z$ "' scaling factor; Hughes and Roughgarden 1998, Tilman 1999, Cottingham et al. 2001, but see also Yachi and Loreau 1999). Modelers need to separate effects of changes in the mean, variance, and covariance on measures of stability used (Lehman and Tilman 2000). This distinction could be important for man- 
agement issues where probability of loss of a function or of maintaining a minimum level of function are concerned.

In short, both heuristic theory and several mathematical models predict that increased diversity will lead to lower variability of ecosystem properties under those conditions in which species respond asynchronously to temporal variation in environmental conditions. While these theoretical studies provide insights about potential mechanisms, they cannot tell us how important these mechanisms are in the real world or whether they saturate at high or low levels of species richness. Key assumptions about equitability of species distributions and the degree of resource partitioning in some models are not necessarily realistic for many ecosystems (Schwartz et al. 2000, Cottingham et al. 2001). Further exploration of the parameter space as these assumptions are relaxed would contribute greatly to our understanding of the conditions under which diversity might be expected to contribute to various aspects of stability in real ecosystems.

2. Experiments and observations.-While theory about effects of species and functional diversity on stability of ecosystem properties is relatively well developed, testing the predictions of this theory is more difficult. Such studies require long-term investigations of communities where differences in species diversity are not confounded by variation in other ecosystem properties, such as soil fertility or disturbance regime. They require observing properties both before and after disturbances or strong environmental fluctuations. And they require many generations of the experimental organisms. For example, among consumer organisms, compensation could take place by either greater per capita consumption or greater population sizes, the latter of which clearly needs time to develop over multiple generations (Ruesink and Srivastava 2001). Because of these difficulties, relatively few experiments have been carried out in the field compared to microcosm studies, in which experiments can be conducted for dozens to hundreds of generations on organisms such as microbes and small invertebrates. Microcosm experiments allow testing of theoretical principles in relatively controlled conditions, though proof that either the theory or microcosm findings apply to the real world requires more work (Naeem 2001). In addition, relatively few experiments, in either microcosms or the field, have been able to completely avoid confounding the effects of species richness with effects of other variables on the measured responses. Despite these limitations, the following consensus points emerge from experimental studies:

(a) In diverse communities, redundancy of functional effect types and compensation among species can buffer process rates in response to changing conditions and species losses.-Considerable evidence exists from field studies in a variety of ecosystems. In lakes, redundancy in species effects on ecosystem properties is a common feature, at least at lower trophic levels (Frost et al. 1995). For example, primary production was relatively constant despite changes in the number and composition of phytoplankton species in response to experimental acidification in a Canadian Shield lake (Schindler et al. 1986). In contrast, changes in species number and composition of higher trophic levels, which generally have lower diversity and therefore less redundancy, often lead to major changes in both community composition and productivity of lower trophic levels in marine and freshwater ecosystems (Schindler et al. 1986, Carpenter and Kitchell 1993, Estes et al. 1998, Vander Zanden et al. 1999, Lodge et al. 2000). Even in diverse communities, however, compensation may not occur among all species in a given trophic level, suggesting that further refinement of functional effect groups beyond trophic position is necessary $(\mathrm{Hu}-$ lot et al. 2000, Duffy et al. 2001, Ruesink and Srivastava 2001).

Experiments that have tried to remove key taxonomic groups in soil food webs have found relatively little change in average process rates such as soil respiration, aboveground net primary production (NPP), and net ecosystem production (Ingham et al. 1985, Liiri et al. 2002). The high diversity of soil organisms and the relatively low degree of specialization in detritivores means that many different species can carry out similar processes (Bradford et al. 2002, but see also Mikola et al. 2002). Loss of redundancy within functional effect groups and its buffering capacity for ecosystem properties may not be apparent until ecosystems have been exposed to multiple types of stresses (Griffiths et al. 2000, de Ruiter et al. 2002).

In aboveground communities, changes in resource availability, temperature, and disturbance regime can be buffered at the ecosystem level by shifts in species composition (Chapin et al. 1996a, Walker et al. 1999). For example, changes in nutrients and temperature led to large shifts in species composition, but relatively little change in total productivity in long-term experiments in Arctic tundra (Chapin and Shaver 1985). Variability in populations appeared to be at least partially responsible for decreased ecosystem variability in response to water availability in Minnesota grasslands (Tilman 1996, 1999, Tilman et al. 2002; but see also point (c), below). Compensation among species of desert rodents clearly stabilized ecosystem properties, although the degree of compensation and stability was not tested across different levels of diversity (Ernest and Brown 2001a). Studies of ecosystem recovery after disturbance have often found that ecosystems with more rapid recovery (i.e., greater resilience) were those 
with a higher diversity of response types (e.g., a mix of seeders and sprouters in the case of fire; Lavorel 1999).

(b) Mechanisms other than compensation can affect stability in response to changing species richness or composition.-Frank and McNaughton (1991) found increased stability of community composition at higher species richness in Yellowstone grasslands, though theory predicts the opposite (May 1974, Tilman 1999, Tilman et al. 2002). Stability of production under drought in bryophyte communities increased with increasing species richness, but resulted from facilitative interactions rather than compensation among species (Mulder et al. 2001). Particular functional traits, such as the degree of nutrient stress tolerance or evolutionary history of exposure to a certain disturbance, can be strong predictors of ecosystem and community response to disturbance, even without invoking species richness or compensatory interactions (MacGillivray et al. 1995, Sankaran and McNaughton 1999, Wardle et al. 2000a). Stability to experimental drought actually decreased with increasing plant species richness in Swiss meadows because of positive effects of nitrogenfixers on overall productivity, but susceptibility of those N-fixers to drought (Pfisterer and Schmid 2002; but see also Schmid and Pfisterer 2003, Wardle and Grime 2003). In agricultural ecosystems, genetic and species diversity of crops and increased diversity of associated insect species can reduce susceptibility of crops to climate variability, pests, pathogens, and invasion of weedy species (e.g., Trenbath 1999, Zhu et al. 2000). However, these patterns also have counterexamples. For example, natural pest control may increase with increasing diversity of associated plant and insect species in some cases (Naylor and Ehrlich 1997), but in others, more diverse settings lead to greater pest populations, e.g., by providing key hosts of high palatability or that allow pests to complete a complex life cycle (Brown and Ewel 1987, Prieur-Richard et al. $2002 b$ ). Such counterexamples suggest that the right combinations of functional attributes, not just diversity effects, often play a major role in determining ecosystem response.

(c) Several experiments that manipulate diversity in the field and in microcosms generally support theoretical predictions that increasing species richness increases stability of ecosystem properties, although most experiments are confounded by other variables (Fig. 5).- The experimental difficulty reflects both the complexity of controlling a variety of potentially confounding variables and ecologists' increased understanding of what those variables are. Stability of plant production, as measured by resistance and/or resilience to nutrient additions, drought, and grazing, increased with the Shannon-Wiener index of diversity $\left(H^{\prime}\right)$ in a variety
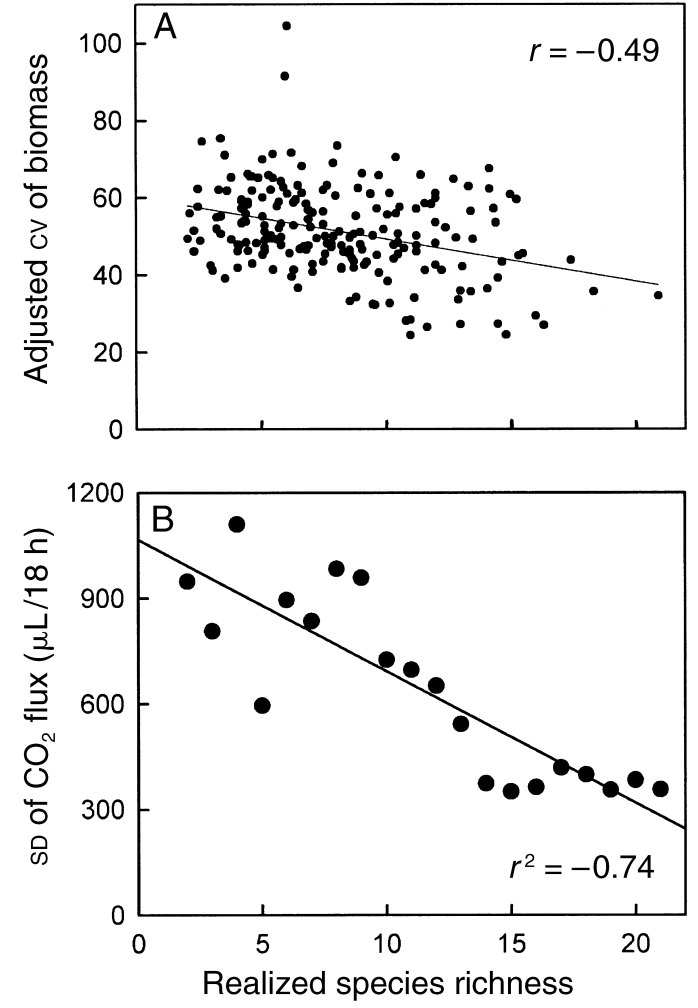

FIG. 5. Increasing stability with increasing species richness in ecological experiments. In both cases, the overall patterns are as predicted from theory, but the underlying mechanisms may coincide only in part (see Section II.B.2). (A) Temporal variability (coefficient of variation, CV) in aboveground plant biomass (correlated with productivity in these Minnesota grasslands) in response to climatic variability (the figure is from Tilman [1999]). The gradient in species richness results from different levels of nutrient addition, so that the stability response may result from differences in species composition instead of, or in addition to, compensatory responses among species (Givnish 1994, Huston 1997). (B) Standard deviation (SD) of net ecosystem $\mathrm{CO}_{2}$ flux in a microbial microcosm (the figure is from McGrady-Steed et al. [1997]). The decrease in variability with increasing diversity may result from both decreased temporal variability and increased compositional similarity among replicates. See also Morin and McGrady-Steed (2004). Composite figure after Loreau et al. (2001).

of successional and herbivore-dominated grasslands (McNaughton 1977, 1985, 1993). However, results of these early experiments may be confounded by a variety of factors, such as differences in species composition and/or abiotic conditions, which also have raised controversy in more recent experiments. For example, in Minnesota grasslands, resistance to loss of plant productivity to drought increased with increasing plant species richness (Tilman and Downing 1994). However, because the species richness gradient in this experiment was caused by nutrient additions, the sta- 
bility response may have resulted as much from composition differences caused by the nutrient additions as from compensation among species (Lepš et al. 1982, Givnish 1994, MacGillivray et al. 1995, Huston 1997, Grime et al. 2000, Pfisterer and Schmid 2002; but see Tilman et al. 1994). Experiments in microcosms and grasslands suggest that increased species richness, either in terms of numbers of different functional groups, or numbers of species within trophic functional groups, can lead to decreased temporal variability in ecosystem properties (McGrady-Steed et al. 1997, Naeem and Li 1997, Petchey et al. 1999, Emmerson et al. 2001, Pfisterer et al. 2004; but see also Pfisterer and Schmid 2002). While species richness or $H^{\prime}$ was statistically significant in all these experiments, species composition (where investigated) had at least an equally strong effect on stability. In some experiments, effects of diversity on temporal variability via compensation or portfolio effects were confounded with effects of compositional similarity among replicates at higher levels of diversity (Wardle 1998). The correlation between compositional similarity and species richness may resemble situations resulting from species loss in real communities (Naeem 1998, Fukami et al. 2001), but determining mechanisms responsible for patterns of ecosystem response becomes problematic.

(d) Explicit demonstration of compensation among species requires careful experimental control and cannot be taken for granted as the mechanism underlying stability responses.-Careful consideration of the questions being asked is required to assess a variety of trade-offs in experimental design for experiments on diversity effects on stability (and magnitudes) of ecosystem properties. Important aspects of experimental design include maximum species richness levels relative to the size of species pool, the degree of exact replication of composition treatments, random selection of species vs. particular scenarios of community assembly/disassembly, and types of statistical analysis (Allison 1999, Emmerson and Raffaelli 2000, Hooper et al. 2002, Huston and McBride 2002, Schmid et al. 2002a).

In sum, the experimental work provides qualified support for the hypothesis that species richness can affect stability of ecosystem properties, although the underlying mechanisms can differ from theoretical predictions and in many cases still need to be fully resolved (Loreau et al. 2001). To this end, a closer linking of theory and experiments would be helpful. Experiments and measurements in natural communities should address explicit predictions and assumptions developed in theoretical models. These include measuring changes in species composition, evenness, correlations among population fluctuations, and values of the scaling factor $z$, as well as ecosystem properties, and com- paring effect and response traits in intact vs. disturbed ecosystems. In addition, more theoretical investigation of the measures of process stability, such as resilience, resistance, and spatial variability, in addition to temporal variability, would help with applicability to experiments. Some of the theory developed for temporal variability may apply to other measures of ecosystem stability, but more exploration of when, where, and why (or why not) is necessary.

\section{Matching experiments with observation}

1. Productivity effects on diversity and vice versa.Species composition and richness both respond to and influence ecosystem processes (Fig. 1). Until recently, studies of the response of diversity to variation in productivity, disturbance regime, or resource availability have been much more common than studies of the response of those processes to variation in diversity. Studies of the former type assess the influence of variation in abiotic factors on species diversity. One pattern that is often observed is a unimodal relationship (the so-called "humpbacked curve") in which species richness is greatest at intermediate levels of resource availability, stress, productivity, or disturbance (Grime 1973b, 1979, 2001, Connell 1978, Huston 1979, 1994, Sousa 1979, Dodson et al. 2000). However, depending on organism type, the intensity of abiotic constraints, and the geographic scale, a variety of patterns can occur, including lower diversity at higher levels of productivity (Waide et al. 1999, Mittelbach et al. 2001). Furthermore, allometric scaling relationships suggest no relationship between plant diversity and total community biomass across a wide variety of tree-dominated communities (Enquist and Niklas 2001, Enquist et al. 2002). How can these observations be reconciled with those experiments in which primary productivity is greater at high species richness?

Essentially, the two approaches ask different questions. Macroecological patterns such as the humpedback relationship are seen in response to gradients of abiotic factors that influence productivity, either across sites or within sites in response to changes in resource supply. Diversity then responds to the resulting abiotic environment and represents the species functional traits for which that environment selects (Grime 1979, Rosenzweig and Abramsky 1993, Ewel 1999, Mittelbach et al. 2001). On the other hand, diversity effects on productivity are primarily observed within sites under similar environmental conditions (Loreau 1998a, Loreau et al. 2001, Schmid 2002). The way the diversity/ ecosystem functioning question was originally framed implied not cross-system comparisons, but changes in diversity within a given system in response to human activities. This difference explains, in part, the predominantly theoretical and manipulative bent of recent 
studies of effects of diversity on ecosystem properties. If the goal is to understand how changes in species richness affect ecosystem properties, one needs gradients in diversity that are not confounded by variation in other potentially important ecosystem controls (see Section II.C.2, below). Such diversity gradients are difficult to find in natural ecosystems.

A synthesis of the local and macroscale perspectives is needed. Anthropogenic changes that lead to species extinctions rarely result in similar environmental conditions in the real world. Community diversity and composition therefore are best viewed as dynamic variables, both responding to and affecting environmental conditions and ecosystem properties. Extinctions of some species may lead to replacements or compensation by others (Brown et al. 2001), and these dynamics can themselves be strong determinants of ecosystem properties (e.g., Ernest and Brown 2001b, Symstad and Tilman 2001, Levine et al. 2003). Changes in ecosystem properties can then feed back to further influence species composition and other ecosystem properties (Fig. 1; Chapin 1980, Hobbie 1992, Chapin et al. 2000). Some evidence suggests that if experimental diversity gradients are not maintained by continuous weeding, the positive relationship between species richness and primary productivity can decay rapidly (Pfisterer et al. 2004). On the other hand, recruitment limitations that cause time lags in colonization by new species could slow re-establishment of a new community (Grime 1998). Even if an effect of reduced diversity was transient, it could still last for decades or longer for longlived communities such as forests. A better understanding of the forces driving patterns of community assembly and disassembly is therefore critical to linking community dynamics to ecosystem properties (Weiher and Keddy 1999b, Thompson et al. 2001, Díaz et al. 2003).

In addition, more effort is needed to reconcile contrasting predictions from cross-system comparisons and local-scale experimental results. For example, while several modeling and experimental studies indicate complementarity among plants (see Section II.A.2, above), Grime (2001) predicts that complementarity will primarily occur where species richness and productivity are positively correlated on the rising part of the unimodal diversity/productivity curve. He argues that effects of legumes on nitrogen availability can skew results if experimental plots do not have time for species richness to equilibrate to the higher fertility induced by $\mathrm{N}$-fixation. These are testable hypotheses that could help resolve the ongoing debate about mechanisms of diversity effects on productivity (see Section II.C.2, below). On another front, allometric scaling relationships (e.g., resource use vs. organism size) are strong across many orders of magnitude, despite ignoring functional differences among species other than size (e.g., Enquist et al. 1998). The overall pattern suggests little effect of functional differentiation or species diversity on ecosystem properties. However, substantial variation (10-100 fold) in the size-resource use regression exists within the scales relevant to local community studies, implying that community interactions, species' functional differences (other than size), and diversity can be ecologically quite significant at such scales (Chapin et al. 1996b, Lavorel and Garnier 2002, Mittelbach et al. 2003, Whittaker and Heegaard 2003). Ecologists need to investigate just how strong the effects of diversity are relative to other ecosystem controls and how such relationships change across ecological scales (see also Section I.C., above).

2. Matching inference with experimental design.The debate about interpretation of experiments (e.g., Huston 1997, Wardle 1999, Huston et al. 2000, Wardle et al. 2000b, Huston and McBride 2002) emphasizes the point that care is needed regarding inferences in both observational and experimental studies about (1) effects of biodiversity relative to abiotic controls and (2) the application of results to real world scenarios of species extinctions. The controversy over experiments comes from two criticisms. First, selective reduction of diversity in response to underlying variables such as fertilization leads to the problem of "hidden treatments" (Huston 1997), which in turn leads to difficulty determining the mechanisms underlying changes in ecosystem response. Experiments incorporating randomized-combinatorial species assemblages became a popular experimental design in response to this problem (Naeem et al. 1995, Hector et al. 1999, Tilman 1999, Schmid et al. 2002a). These experiments attempt to understand the functional consequences of species loss from a regional pool (Vitousek and Hooper 1993, Lawton 1994, Naeem et al. 1995, Sala et al. 1996), for which random, synthetic communities provide one means of exploring the space of "possible communities."

The primary issue is how to interpret such approaches in the context of actual scenarios of biodiversity change, which is the second criticism leveled at synthetic community studies. The randomized-assemblage experimental design may not resemble the way real communities are assembled (or disassembled, in the case of extinctions; Wardle et al. 2000b) and it creates a complex experiment with multiple autocorrelations (Huston and McBride 2002, Naeem 2002a). Such difficulties, in combination with the hidden treatments issue, mean that experimental designs must be closely matched to the primary aims and hypotheses of each study (Schmid et al. 2002a).

The relevance of any such experiments to the real world depends on the drivers of community change and the patterns of species loss or introduction. Species 
losses may or may not be random with respect to species' effects on ecosystem properties, depending on whether traits related to response to the environment also affect ecosystem properties (Grime 1979, Chapin 1980, Fridley 2001, Lavorel and Garnier 2002). In some studies, for example, the best predictor variables for plant extinction are life-history characteristics such as low seed dormancy, short life cycle, and absence of clonality, which are often independent of functional traits influencing ecosystem properties (e.g., Chapin et al. 1996a, Grime et al. 1997a, Stöcklin and Fischer 1999). In such cases, randomized combinatorial experiments may provide a reasonable approximation to actual extinction scenarios (Loreau et al. 2001).

On the other hand, losses in plant and animal diversity are often not random and often do not occur against an unchanging abiotic background. Species can be lost from particular sites by the same processes that are destroying or transforming the ecosystems that contain them, resulting in functional shifts in the biota. That is, sets of species with particular functional traits are being replaced by other sets with different traits (Ratcliffe 1984, Thompson 1994, Janssens et al. 1998). In such cases, random scenarios could be misleading because differences in extinction probability among species may be driven by species' traits directly linked to effects on processes (Duncan and Young 2000). For example, nutrient enrichment consistently selects for fast-growing species that outcompete slower-growing, more stress-tolerant species (Tilman 1987, Aerts et al. 1990, Wedin and Tilman 1993, MacGillivray et al. 1995). Given this consistency of diversity and dominant species' traits across gradients of nitrogen deposition, the debate about effects of species richness vs. composition in some experiments (Givnish 1994, Tilman and Downing 1994, Huston 1997) may be moot from the perspective of managing nitrogen within landscapes. Additional research is needed to understand how the functional traits of species interact with different types of human-caused environmental changes to determine pathways of species loss (Sala et al. 2000, Chapin et al. 2001). How might these pathways of species loss influence various ecosystem properties and services? How might these changes feed back to further biodiversity changes?

Using a variety of experimental approaches will contribute to robust answers to these questions. Removal experiments offer potential to address such questions because they directly explore what happens to an ecosystem when a species or functional type is no longer present (e.g., Sala et al. 1989, Hobbie et al. 1999, Wardle et al. 1999, Symstad and Tilman 2001, Díaz et al. 2003). Of course, manipulative experiments, using either synthetic communities or species removals, have other constraints, such as being restricted to easily ma- nipulated ecosystem types, time needed for establishment or disturbance recovery, and other issues associated with scale and realism such as being too small, too brief, or too simple in structure when compared to natural systems. For example, natural patterns of spatial aggregation of species can be an important factor affecting both species coexistence and, potentially, ecosystem properties (e.g., Freckleton and Watkinson 2000, Stoll and Prati 2001). For these reasons, there is an urgent need for observational studies carefully designed to determine whether the patterns and mechanisms predicted by theories and experiments occur in natural systems (Troumbis and Memtsas 2000, but see also Wardle 2001b).

\section{Management Implications}

Biodiversity, whether at the level of genes, species, or communities, clearly affects the way ecosystems function, as outlined in the preceding sections. The protection of ecosystem goods and services already forms an important part of environmental theory and practice (Daily 1997). Wildlife and habitat conservation, the Convention on Biodiversity, intergovernmental panels and agencies, and international scientific programs represent widespread activities designed to understand and reduce biodiversity loss and species invasions. Incorporating what we know about the basic roles that biodiversity can play in ecosystem properties can help to inform the development of more effective environmental management and policy, and improve our abilities to predict environmental change. Yet, if diversity is so often crucial to sustained functioning of ecosystems, why is it not always a routine part of management philosophy for farmers, ranchers, fishers, and foresters?

In this section, we seek to address this question, and to suggest areas in which application of the principles discussed in Section II might be most beneficially applied. Our aim is to be suggestive, rather than exhaustive, in coverage. The needs for knowledge on biodiversity's effects on ecosystem properties and services clearly depend on the type of management questions being addressed. These questions cover a huge range of activities and scales, from small-scale, local issues (e.g., how many and which species might be necessary to produce food and reduce erosion for a farmer in the tropics), to regional issues (e.g., how to manage forest lands for wood production, fish and wildlife habitat, and recreation), to global issues (e.g., how might shifts in species composition and diversity associated with climate change influence carbon sequestration in the biosphere). We discuss a few key examples in hopes of illustrating potential applications. Here, we differentiate managed ecosystems from merely degraded ecosystems ("polluted, overexploited, or converted 


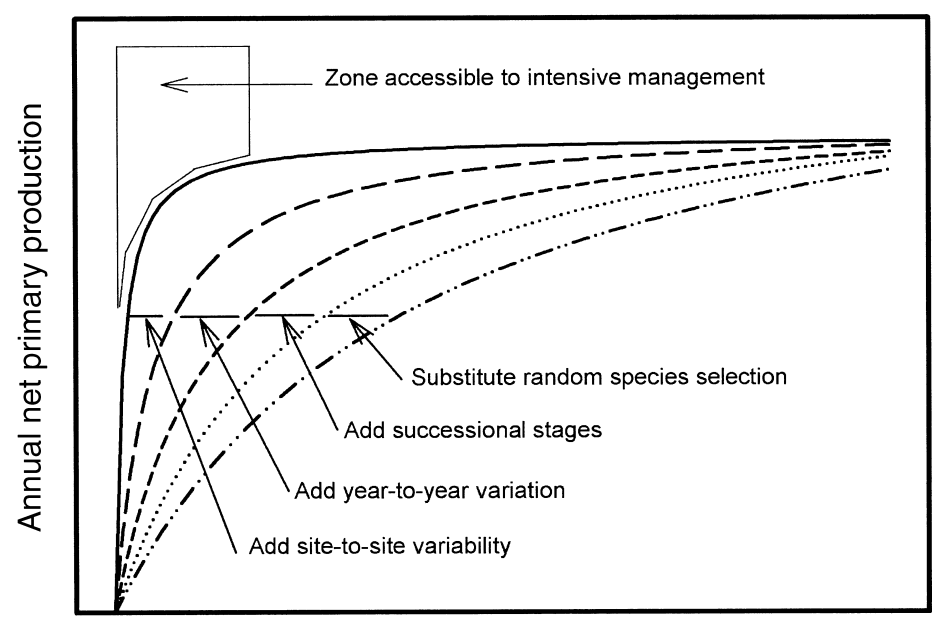

Species richness of dominant life-form

FIG. 6. Anticipated effects of diversity on ecosystem properties (plant net primary productivity is shown) across increasing scales. As habitat heterogeneity, temporal variation in conditions, and response to disturbance are included, more species are needed to saturate ecosystem properties. If species are selected at random, rather than chosen according to their adaptations, ecosystem properties may saturate even more slowly. "Zone accessible to intensive management" reflects agronomic ecosystems where very high productivity may be achieved at very low species richness, but at the cost of substantial inputs of time, energy, fertilizers, pesticides, and/or water resources, often with concurrent off-site impacts and trade-offs with other ecosystem services. The figure is modified from Field (1995).

that have not been managed"; cf. Silver et al. 2001). While systems that are intensively managed for production differ in many respects from lightly managed natural and seminatural ecosystems, application of the principles discussed in Section II is similar in some critical situations, particularly those involving increases of scale.

In general, management of production-oriented systems has focused on composition (the species or genotypes that perform best under a given set of conditions) rather than species diversity. Lack of diversity in intensively managed systems occurs for a simple reason: diversity, whether of genotypes, species, or communities, often complicates management, making it less profitable in the short term (Ewel 1991). Especially with industrialized agriculture, diversity poses problems for automated planting and harvesting and efficiencies of scale, and this is not a cost that many enterprises are willing to incur. The ecological perspectives of more complete resource utilization or ability to sustain natural levels of biodiversity are seldom incorporated into the decision-making process, either at the levels of individuals or government policy. Uniformity has been the rule, and it tends to be driven by economic, not ecological, considerations (Ewel 1991).

Given the apparent conflict between near-term profits and longer term sustainability, are we inevitably headed for a world whose oceans are managed for a handful of pelagic fishes and whose lands are a simplified patchwork of soybeans, cows, wheat, rice, pines, eucalypts, corn, concrete, and cosmopolitan weeds? No, as long as broader scale factors are incorporated into calculations of management costs. Maintenance of high productivity over time in monocultures almost invariably requires heavy subsidies of chemicals, energy, and capital (Fig. 6; Field 1995), and it may not be possible or sustainable in some systems in the face of various disturbances, diseases, soil erosion, overuse of natural capital (e.g., water), or trade-offs with other ecosystem services (Ewel 1999, Postel 1999). Diversity becomes increasingly important as a management goal, from both economic and ecological perspectives, with increasing temporal and spatial scales and for providing a broader array of ecosystem services.

Diversity is consciously incorporated into ecosystems managed for extraction of food and fiber under at least three circumstances: (1) as a safeguard against risk resulting from, for example, fluctuations in environmental conditions or marketplace demands; (2) as a means of extending use of a site's resources over time; and (3) as a means to provide multiple goods and services. A variety of practices illustrate these exceptions to "management by imposed homogeneity" in intensively managed systems, ranging from multipleuse forests and rangelands, to intercropping and agroforestry, to the home gardens so common in many tropical countries. For example, home gardens provide a variety of food, medicinal, and construction materials (e.g., Watson and Eyzaguirre 2002), and public management of forests provides for a variety of goods and 
services, including many that are non-extractive. Genetic diversity of crops decreases susceptibility to pests and climate variation (Ewel 1986, Altieri 1990, Zhu et al. 2000). Especially in low-input systems, locally adapted varieties often produce higher yield or are more resistant to pests than varieties bred for high performance under optimal conditions (Joshi et al. 2001). Intercropping, crop rotations, and mixed-species forestry often include legumes to increase soil nutrient capital (Trenbath 1974, Vandermeer 1989, Cannell et al. 1992). Diversity of pasture species can reduce nutrient leaching, production variation, and insurance costs (Schläpfer and Erikson 2001, Mäder and Fliessbach 2002, Schläpfer et al. 2002). In all of these cases, more knowledge-based, biologically detailed management may require greater short-term effort or expense, but with the benefit of longer term sustainability and/ or reduced off-site impacts.

Increasing the temporal scale of management is relevant in less intensively managed systems as well. For example, concern about carbon dioxide emissions into the atmosphere has generated substantial discussion about reducing the net impact of those emissions through biotic sequestration. If it is to be effective, carbon sequestration must be a long-term undertaking, involving sustainable rates of fixation and storage. High rates of net primary production (NPP) that one might witness from a monoculture in the short term are likely to drop with time, or at least oscillate considerably, as pest attacks, cohort senescence, and weather variability take their tolls. As discussed in Section II.B., diversity can provide compensatory capability required over time if an ecosystem is to sustain $\mathrm{C}$ sequestration (e.g., Bolker et al. 1995), including responses of NPP to elevated $\mathrm{CO}_{2}$ and nitrogen (Stocker et al. 1999, Niklaus et al. 2001b, Reich et al. 2001, He et al. 2002). NPP is only half the story, however. Net ecosystem production (NEP; total $\mathrm{C}$ uptake minus all $\mathrm{C}$ losses, both autotrophic and heterotrophic) is the critical measure for $\mathrm{C}$ sequestration (Catovsky et al. 2002). We have considerably less information about plant diversity effects on the suite of processes influencing $\mathrm{C}$ losses from ecosystems, such as decomposition and heterotrophic respiration, than for NPP (see Section II.A.2). Additional research on whole system $\mathrm{C}$ cycling in response to varying plant diversity is a critical need for the future (Catovsky et al. 2002, Dias et al. 2003).

The need for incorporating diversity also arises when considering management over large spatial scales and for multiple ecosystem services. The importance of functional diversity at the ecosystem or landscape scale is well known in a number of specific cases. For example, areas of natural habitat can serve as sources of propagules for recolonization of sites affected by other stresses (Cushman et al. 1995). Considering the species-area relationship, higher species diversity at the landscape scale is necessary to maintain even moderate diversity at the local scale (Wilson and Willis 1975). Connectedness among a variety of ecosystem types is necessary for some far-ranging species such as migratory birds and fish, and for predators with alternate prey, some of which may be agricultural pests (Cushman et al. 1995, Perfecto et al. 1996, Greenberg et al. 1997). In all these cases, effects may be mediated by a diversity of species or by particularly strong effects of a given species or functional type (Noble and Burke 1995). For parks and preserves managed for biodiversity preservation, potential effects of climate change on species' ranges necessitate managing diversity at the landscape to regional scale. As climate patterns change, the organisms best adapted to a particular suite of environmental conditions may find themselves unable to migrate from recently changed conditions (e.g., Etterson and Shaw 2001). The need for diversity at large spatial scales is already being implemented in the conservation community (e.g., see the Conservation by Design Initiative of The Nature Conservancy and the Global 200 Ecoregions of the World Wildlife Fund), but it is not yet widely recognized by those engaged in management for food and fiber.

In intensively managed systems, management choices influence the diversity of associated species as well as those species targeted for harvest, both within the harvesting area and in the surrounding landscape (Fig. 7; Fischer and Stöcklin 1997, Giller et al. 1997, Gonzalez et al. 1998, Vandermeer et al. 1998, 2002, Stöcklin and Fischer 1999, Vandermeer and Carvajal 2001). Changes in composition and diversity of associated species have potential consequences for forest or agricultural production via supporting ecosystem services (e.g., generation of soil fertility, pest control, pollination), as well as for additional services (e.g., provision of wildlife habitat) (Pimentel et al. 1992, Nabhan and Buchmann 1997, Naylor and Ehrlich 1997). There are many management strategies for increasing diversity of associated species (e.g., Hanson et al. 1991, Pimentel et al. 1992), which is often important for biodiversity value itself. However, the net effects on production of target species are variable, depending on the particular functional relationships among the species involved, as discussed above (Section II.B.2(b); Ewel 1986, Vandermeer et al. 2002). Effects of diversity on pest and pathogens are not restricted to agricultural situations. In deciduous forests of eastern North America, shifts in trophic relations among mammals can affect the degree to which humans are exposed to Lyme disease and other pathogens (Ostfeld and Keesing 2000). Theory predicts that under some conditions mammalian diversity is an important component of the 


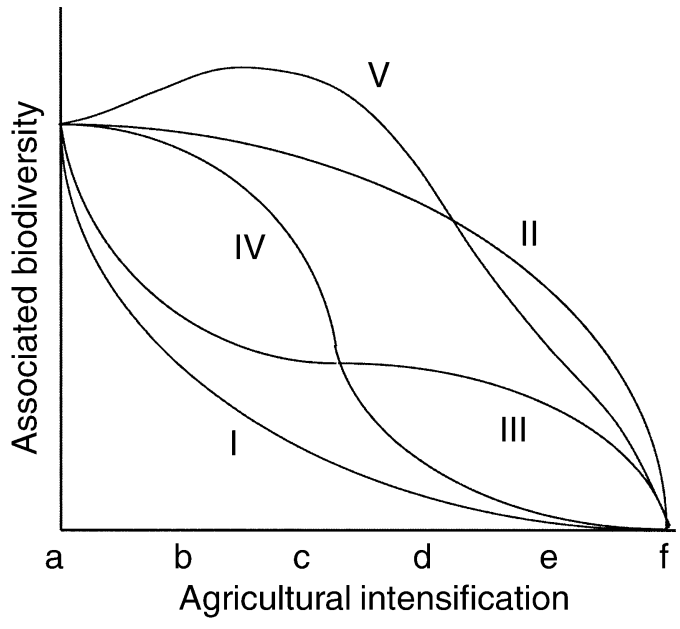

FIG. 7. Potential patterns of effects of intensification of agricultural practices on diversity of nontarget species. Letters a-f on the $x$-axis refer to increasing states of management intensity, with "a" being an unmanaged ecosystem and "f " being intensive, industrialized agriculture. Intensification tends to reduce diversity of associated taxa, although the patterns could follow a variety of trajectories, including the potential for initial increases in species richness for some taxa under the assumptions of the intermediate disturbance hypothesis (Giller et al. 1997). Losses of associated diversity may thereby affect ecosystem services related to agricultural production, although the effects often depend on the details of the relationships among the species and services in question (see Section III). The figure is modified from Vandermeer et al. (2002).

response, but under other conditions, the functional traits of certain key species have a dominant effect on disease prevalence (Schmid and Ostfeld 2001).

Management for multiple goals or functions becomes more complicated because of potential trade-offs among them. At what points (e.g., across a gradient of intensified land use) might species be lost whose effects on services either cannot be replaced, or are very expensive to replace? What are the ecological and economic trade-offs associated with these losses (e.g., Balmford et al. 2002)? Understanding which species (both target and associated) affect which ecosystem properties and services will help in this regard, but it may take many years to understand fully. In the interim, adaptive management and maintaining a diversity of native species will help maintain future management options.

Biodiversity, broadly defined, clearly has strong effects on ecosystem properties and the goods and services derived from them. Similarly, there is no debate about the effects of the functional characteristics of particular species. Most controversy has surrounded the effects of species richness, which are more variable. Yet, despite some mechanistic uncertainties and the economic complexities caused by incorporating genetic, species, and community diversity into management, there is little doubt that this needs to be done, especially in making decisions involving large temporal and spatial scales. Sacrificing those aspects of ecosystems that are difficult or impossible to reconstruct, such as diversity, simply because we are not yet certain about the extent and mechanisms by which they affect ecosystem properties, will restrict future management options even further (Costanza et al. 1998, Lauck et al. 1998). It is incumbent upon ecologists to communicate this need, and the values that can derive from such a perspective, to those charged with economic and policy decision-making.

\section{SUMMARY}

Human-induced changes to components of the Earth's biodiversity have the potential to compromise the performance of ecosystems, both immediately and by impeding their ability to respond to altered conditions. A long history of ecological experimentation and theory supports the postulate that ecosystem goods and services, and the ecosystem properties from which they are derived, depend on biodiversity, broadly defined. Functional traits of species are important drivers of ecosystem properties, and we are learning more about how these traits combine to affect properties in more diverse systems. While the debate surrounding some experiments on the effects of plant species richness on ecosystem properties has received some negative press, in the end it has helped broaden and deepen ecological understanding and point the way for future studies integrating both community and ecosystem perspectives (Loreau et al. 2001, 2002b, Kinzig et al. 2002, Naeem $2002 b$ ). Species composition, richness, evenness, and interactions all both respond to and influence ecosystem properties. Further progress will require integration of knowledge about how communities are structured with knowledge about controls on ecosystem properties. To make links to ecosystem management, further understanding of the social and economic constraints of potential practices needs to be integrated with our ecological knowledge (e.g., the Millenium Ecosystem Assessment, available online). ${ }^{18}$ The mechanisms of biodiversity effects are likely to differ among ecosystem properties, ecosystem types, management goals, and pathways of potential biodiversity changes. Understanding this complexity, while taking strong steps to minimize current losses and invasions of species, is an important step toward our ability to responsibly manage Earth's ecosystems and the diverse biota they contain.

\footnotetext{
${ }^{18}\langle\mathrm{http}: / / \mathrm{www} . \mathrm{millenniumassessment.org/en/index.aspx}\rangle$
} 


\section{ACKNOWLEDGMENTS}

Peter Vitousek contributed greatly to the committee process. Phil Grime, Michael Huston, Christa Mulder, Peter Vitousek, and an anonymous reviewer provided extensive comments on earlier drafts of the manuscript. Phil Grime also participated in the initial meeting and formulation of this document. Tim Kreps gathered and helped interpret literature. Katherine Cottingham, Peter Morin, and David Tilman contributed figures. The initial committee meeting and ideas for the paper benefited greatly from the conference "Biodiversity and ecosystem functioning: synthesis and perspectives," 69 December 2000, organized by Michel Loreau, Shahid Naeem, and Pablo Inchausti under the auspices of IGBPGCTE Focus 4 and DIVERSITAS Core Programme Element 1, and funded by the European Science Foundation, the Centre National de la Recherche Scientifique (France), and the National Science Foundation (USA). Anonymous donors to the Ecological Society of America provided additional meeting support. Partial support for D. Hooper came from NSF grants DEB-9974159 and DEB-0213187.

\section{Literature Cited}

Aarssen, L. W. 1997. High productivity in grassland ecosystems: affected by species diversity or productive species? Oikos 80:183-184.

Aerts, R., F. Berendse, H. Decaluwe, and M. Schmitz. 1990 Competition in heathland along an experimental gradient of nutrient availability. Oikos 57:310-318.

Alban, D. H., and E. C. Berry. 1994. Effects of earthworm invasion on morphology, carbon, and nitrogen of a forest soil. Applied Soil Ecology 1:243-249.

Allison, G. W. 1999. The implications of experimental design for biodiversity manipulations. American Naturalist 153 $26-45$.

Altieri, M. A. 1990. Why study traditional agriculture? Pages 551-564 in C. R. Carrol, J. H. Vandermeer, and P. M. Rosset, editors. Agroecology. McGraw Hill, New York, New York, USA.

Andrén, O., M. Clarholm, and J. Benstsson. 1995. Biodiversity and species redundancy among litter decomposers Pages 141-151 in H. A. Collins, G. P. Robertson, and M. J. Klug, editors. The significance and regulation of soil biodiversity. Kluwer, Dordrecht, The Netherlands.

Balmford, et al. 2002. Economic reasons for conserving wild nature. Science 297:950-953.

Balser, T. C., A. Kinzig, and M. K. Firestone. 2002. Linking soil microbial communities and ecosystem functioning. Pages 265-293 in A. Kinzig, S. W. Pacala, and D. Tilman, editors. The functional consequences of biodiversity: empirical progress and theoretical extensions. Princeton University Press, Princeton, New Jersey, USA.

Barbier, E. B., et al. 1995. The economic value of biodiversity. Pages 823-914 in V. Heywood and United Nations Environment Programme (UNEP), editors. Global biodiversity assessment. Cambridge University Press, Cambridge, UK.

Bardgett, R. D., and A. Shine. 1999. Linkages between plan litter diversity, soil microbial biomass and ecosystem function in temperate grasslands. Soil Biology and Biochemistry 31:317-321.

Bazzaz, F. A. 1987. Experimental studies on the evolution of niche in successional plant populations. Pages 245-272 in A. J. Gray, M. J. Crawley, and P. J. Edwards, editors. Colonization, succession and stability. Blackwell Scientific, Oxford, UK.
Berendse, F. 1982. Competition between plant populations with different rooting depths III. Field experiments. Oecologia 53:50-55.

Berendse, F. 1983. Interspecific competition and niche differentiation between Plantago lanceolata and Anthoxanthum odoratum in a natural hayfield. Journal of Ecology 71:379-390.

Berendse, F., and W. T. Elberse. 1990. Competition and nutrient availability in heathland and grassland ecosystems. Pages 93-116 in J. B. Grace and D. Tilman, editors. Perspectives on plant competition. Academic Press, San Diego, California, USA.

Berendse, F., H. Oudhof, and J. Bol. 1987. A comparative study on nutrient cycling in wet heathland ecosystems I. Litter production and nutrient losses from the plant. Oecologia 74:174-184.

Berkowitz, A. R., C. D. Canham, and V. R. Kelly. 1995. Competition vs. facilitation of tree seedling growth and survival in early successional communities. Ecology 76: 1156-1168.

Berlow, E. L. 1999. Strong effects of weak interactions in ecological communities. Nature 398:330-334.

Bertness, M. D., and R. Callaway. 1994. Positive interactions in communities. Trends in Ecology and Evolution 9:191193.

Blair, J. M., R. W. Parmelee, and M. H. Beare. 1990. Decay rates, nitrogen fluxes, and decomposer communities of single- and mixed-species foliar litter. Ecology 71:1976-1985.

Bolker, B. M., S. W. Pacala, F. A. Bazzaz, C. D. Canham, and S. A. Levin. 1995. Species diversity and ecosystem response to carbon dioxide fertilization: conclusions from a temperate forest model. Global Change Biology 1:373381.

Box, E. O. 1996. Plant functional types and climate at the global scale. Journal of Vegetation Science 7:309-320.

Bradford, M. A., et al. 2002. Impacts of soil faunal community composition on model grassland ecosystems. Science 298:615-618.

Brown, B. J., and J. J. Ewel. 1987. Herbivory in complex and simple tropical successional ecosystems. Ecology 68 : $108-116$.

Brown, J. H., S. K. M. Ernest, J. M. Parody, and J. P. Haskell. 2001. Regulation of diversity: maintenance of species richness in changing environments. Oecologia 126:321-332.

Bruno, J. F., J. J. Stachowicz, and M. D. Bertness. 2003. Inclusion of facilitation into ecological theory. Trends in Ecology and Evolution 18:119-125.

Callaway, R. M., et al. 2002. Positive interactions among alpine plants increase with stress. Nature 417:844-848.

Cannell, M. G. R., D. C. Malcolm, and P. A. Robertson, editors. 1992. The ecology of mixed species stands. Blackwell Scientific, Oxford, UK.

Cardinale, B. J., K. Nelson, and M. A. Palmer. 2000. Linking species diversity to the functioning of ecosystems: on the importance of environmental context. Oikos 91:175-183.

Cardinale, B. J., M. A. Palmer, and S. A. Collins. 2002. Species diversity enhances ecosystem functioning through interspecific facilitation. Nature 415:426-429.

Carpenter, S. R., and J. F. Kitchell, editors. 1993. The trophic cascade in lakes. Cambridge University Press, Cambridge, UK.

Carpenter, S. R., J. F. Kitchell, J. R. Hodgson, P. A. Cochran, J. J. Elser, M. M. Elser, D. M. Lodge, D. Kretchmer, X. He, and C. N. von Ende. 1987. Regulation of lake primary productivity by food web structure. Ecology 68:18631876. 
Casperson, J. P., and S. W. Pacala. 2001. Successional diversity and forest ecosystem function. Ecological Research 16:895-904.

Catovsky, S., M. A. Bradford, and A. Hector. 2002. Biodiversity and ecosystem productivity: implications for carbon storage. Oikos 97:443-448.

Chapin, F. S., III. 1980. The mineral nutrition of wild plants. Annual Review of Ecology and Systematics 11:233-260.

Chapin, F. S., III, K. Autumn, and F. Pugnaire. 1993. Evolution of suites of traits in response to environmental stress. American Naturalist 142:S78-S92.

Chapin, F. S., III, S. M. Bret-Harte, S. E. Hobbie, and H. Zhong. 1996a. Plant functional types as predictors of transient responses of arctic vegetation to global change. Journal of Vegetation Science 7:347-358.

Chapin, F. S., III, P. A. Matson, and H. Mooney. 2002. Principles of terrestrial ecosystem ecology. Springer-Verlag, New York, New York, USA.

Chapin, F. S., III, H. Reynolds, C. D'Antonio, and V. Eckhart. $1996 \mathrm{~b}$. The functional role of species in terrestrial ecosystems. Pages 403-428 in B. Walker and W. Steffen, editors. Global change in terrestrial ecosystems. Cambridge University Press, Cambridge, UK.

Chapin, F. S., III, O. E. Sala, and E. Huber-Sannwald, editors. 2001. Global biodiversity in a changing environment: scenarios for the 21st century. Springer-Verlag, New York, New York, USA.

Chapin, F. S., III, and G. R. Shaver. 1985. Individualistic growth response of tundra plant species to environmental manipulations in the field. Ecology 66:564-576.

Chapin, F. S., III, M. S. Torn, and M. Tateno. 1996c. Principles of ecosystem sustainability. American Naturalist 148: $1016-1037$.

Chapin, F. S., III, P. M. Vitousek, and K. Van Cleve. 1986. The nature of nutrient limitation in plant communities. American Naturalist 127:48-58.

Chapin, F. S., III, B. H. Walker, R. J. Hobbs, D. U. Hooper, J. H. Lawton, O. E. Sala, and D. Tilman. 1997. Biotic control over the functioning of ecosystems. Science 277: 500-504.

Chapin, F. S., III, L. R. Walker, C. L. Fastie, and L. C. Sharman. 1994. Mechanisms of primary succession following deglaciation at Glacier Bay, Alaska. Ecological Monographs 64:149-175.

Chapin, F. S., III, E. S. Zavaleta, V. T. Eviner, R. L. Naylor, P. M. Vitousek, H. L. Reynolds, D. U. Hooper, S. Lavorel, O. E. Sala, S. E. Hobbie, M. C. Mack, and S. Diaz. 2000. Consequences of changing biodiversity. Nature 405:234242.

Chapman, K., J. B. Whittaker, and O. W. Heal. 1988. Metabolic and faunal activity in litters of tree mixtures compared with pure stands. Agriculture, Ecosystems and Environment 24:33-40.

Chesson, P. L. 2000. Mechanisms of maintenance of species diversity. Annual Review of Ecology and Systematics 31: 343-366.

Chesson, P., S. Pacala, and C. Neuhauser. 2002. Environmental niches and ecosystem functioning. Pages 213-245 in A. Kinzig, D. Tilman, and S. Pacala, editors. Functional consequences of biodiversity: experimental progress and theoretical extensions. Princeton University Press, Princeton, New Jersey, USA.

Christensen, N. L., et al. 1996. The report of the Ecological Society of America Committee on the Scientific Basis for Ecosystem Management. Ecological Applications 6:665691.
Connell, J. H. 1978. Diversity in rain forests and coral reefs. Science 199:1302-1310.

Connell, J. H., and R. O. Slatyer. 1977. Mechanisms of succession in natural communities and their role in community stability and organization. American Naturalist 111:11191144.

Connolly, J. 1986. On difficulties with replacement-series methodology in mixture experiments. Journal of Applied Ecology 23:125-137.

Costanza, R., et al. 1998. Principles for sustainable governance of the oceans. Science 281:198-199.

Cottingham, K. C., B. L. Brown, and J. T. Lennon. 2001. Biodiversity may regulate the temporal variability of ecological systems. Ecology Letters 4:72-85.

Cousens, R., and M. O'Neill. 1993. Density dependence of replacement series experiments. Oikos 66:347-352.

Cramer, W. 1997. Using plant functional types in a global vegetation model. Pages 271-288 in T. M. Smith, H. H. Shugart, and F. I. Woodward, editors. Plant functional types: their relevance to ecosystem properties and global change. Cambridge University Press, Cambridge, UK.

Cushman, J. H., R. Dirzo, A. C. Janetos, J. Lubchenco, H. A. Mooney, and O. E. Sala. 1995. Biodiversity and ecosystem functioning: ecosystem analyses. Section 6.3, Conclusions. Pages 446-452 in United Nations Environment Programme (UNEP), editor. Global biodiversity assessment. Cambridge University Press, Cambridge, UK.

Daily, G., editor. 1997. Nature's services. Societal dependence on natural ecosystems. Island Press, Washington, D.C., USA.

D'Antonio, C. M. 2000. Fire, plant invasions, and global changes. Pages 65-94 in H. A. Mooney and R. J. Hobbs, editors. Invasive species in a changing world. Island Press, Covelo, California, USA.

D'Antonio, C. M., and P. M. Vitousek. 1992. Biological invasions by exotic grasses, the grass-fire cycle, and global change. Annual Review of Ecology and Systematics 23: 63-87.

de Ruiter, P. C., B. Griffiths, and J. C. Moore. 2002. Biodiversity and stability in soil ecosystems: patterns, processes and the effects of disturbance. Pages 102-113 in M. Loreau, S. Naeem, and P. Inchausti, editors. Biodiversity and ecosystem functioning: synthesis and perspectives. Oxford University Press, Oxford, UK

de Ruiter, P. C., A. M. Neutel, and J. C. Moore. 1994. Modelling food webs and nutrient cycling in agro-ecosystems. Trends in Ecology and Evolution 9:378-383.

de Ruiter, P. C., A. M. Neutel, and J. C. Moore. 1995. Energetics, patterns of interaction strengths, and stability in real ecosystems. Science 269:1257-1260.

Dias, B., S. Díaz, M. McGlone, A. Hector, D. A. Wardle, G. Ruark, H. Gitay, H. Toivonen, I. Thompson, K. J. Mulongoy, P. Straka, and V. Burianek. 2003. Biodiversity: linkages to climate change. Pages 24-37 in R. Watson and O. Berghal, editors. Interlinkages between biological diversity and climate change and advice on the integration of biodiversity considerations into the implementation of the United Nations Framework Convention on Climate Change and its Kyoto Protocol. Convention on Biological Diversity, Montreal, Canada.

Díaz, S., and M. Cabido. 2001. Vive la différence: plant functional diversity matters to ecosystem processes. Trends in Ecology and Evolution 16:464-655.

Díaz, S., M. Cabido, and F. Casanoves. 1998. Plant functional traits and environmental filters at a regional scale. Journal of Vegetation Science 9:113-122. 
Díaz, S., M. Cabido, and F. Casanoves. 1999. Functional implications of trait-environment linkages in plant communities. Pages 338-362 in E. Weiher and P. Keddy, editors. Ecological assembly rules: perspectives, advances, retreats. Cambridge University Press, Cambridge, UK.

Díaz, S., A. J. Symstad, F. S. Chapin, III, D. A. Wardle, and L. F. Huenneke. 2003. Functional diversity revealed by removal experiments. Trends in Ecology and Evolution 18: 140-146.

Doak, D. F., D. Bigger, E. K. Harding, M. A. Marvier, R. E. O'Malley, and D. Thomson. 1998. The statistical inevitability of stability-diversity relationships in community ecology. American Naturalist 151:264-276.

Dodson, S. I., S. E. Arnott, and K. L. Cottingham. 2000. The relationship in lake communities between primary productivity and species richness. Ecology 81:2662-2679.

Downing, A. L., and M. A. Leibold. 2002. Ecosystem consequences of species richness and composition in pond food webs. Nature 416:837-841.

Drake, J. M. 2003. Why does grassland productivity increase with species richness? Disentangling species richness and composition with tests for overyielding and superyielding in biodiversity experiments. Proceedings of the Royal Society of London, Series B 270:1713-1719.

Duffy, J. E., and M. E. Hay. 2000. Strong impacts of grazing amphipods on the organization of a benthic community. Ecological Monographs 70:237-263.

Duffy, J. E., K. S. MacDonald, J. M. Rhode, and J. D. Parker. 2001. Grazer diversity, functional redundancy, and productivity in seagrass beds: an experimental test. Ecology 82:2417-2434.

Dukes, J. S. 2001a. Biodiversity and invasibility in grassland microcosms. Oecologia 126:563-568.

Dukes, J. S. 2001b. Productivity and complementarity in grassland microcosms of varying diversity. Oikos 94:468480.

Duncan, R. P., and J. R. Young. 2000. Determinants of plant extinction and rarity 145 years after European settlement of Auckland, New Zealand. Ecology 81:3048-3061.

Elmqvist, T., C. Folke, M. Nyström, G. Peterson, J. Bengtsson, B. Walker, and J. Norberg. 2003. Response diversity, ecosystem change, and resilience. Frontiers in Ecology and the Environment 1:488-494.

Elser, J. J., D. R. Dobberfuhl, N. A. MacKay, and J. H. Schampel. 1996. Organism size, life history and N:P stoichiometry. BioScience 46:674-684.

Elton, C. S. 1958. The ecology of invasions by animals and plants. Methuen, London, UK.

Emmerson, M. C., and D. Raffaelli. 2000. Detecting the effects of diversity on measures of ecosystem function: experimental design, null models and empirical observations. Oikos 91:195-203.

Emmerson, M. C., M. Solan, C. Emes, D. M. Peterson, and D. Raffaelli. 2001. Consistent patterns and the idiosyncratic effects of biodiversity in marine ecosystems. Nature 411:73-77.

Engelhardt, K. A. M., and M. E. Ritchie. 2001. Effects of macrophyte species richness on wetland ecosystem functioning and services. Nature 411:687-689.

Engelhardt, K. A. M., and M. E. Ritchie. 2002. The effect of aquatic plant species richness on wetland ecosystem processes. Ecology 83:2911-2924.

Enquist, B. J., J. H. Brown, and G. B. West. 1998. Allometric scaling of plant energetics and population density. Nature 395: 163-165.

Enquist, B. J., J. P. Haskell, and B. H. Tiffney. 2002. General patterns of taxonomic and biomass partitioning in extant and fossil plant communities. Nature 419:610-613.
Enquist, B. J., and K. J. Niklaus. 2001. Invariant scaling relations across tree-dominated communities. Nature 410: 655-660.

Enserink, M. 1999. Predicting invasions: biological invaders sweep in. Science 285:1834-1836.

Ernest, S. K. M., and J. H. Brown. 2001a. Delayed compensation for missing keystone species by colonization. Science 292:101-104.

Ernest, S. K. M., and J. H. Brown. 2001b. Homeostasis and compensation: the role of species and resources in ecosystem stability. Ecology 82:2118-2132.

Estes, J. A., M. T. Tinker, T. M. Williams, and D. F. Doak. 1998. Killer whale predation on sea otters linking oceanic and nearshore ecosystems. Science 282:473-476.

Etterson, J. R., and R. G. Shaw. 2001. Constraint to adaptive evolution in response to global warming. Science 294:151154.

Ewel, J. J. 1986. Designing agroecosystems for the humid tropics. Annual Review of Ecology and Systematics 17: 245-271.

Ewel, J. J. 1991. Yes, we got some bananas. Conservation Biology 5:423-425.

Ewel, J. J. 1999. Natural systems as models for the design of sustainable systems of land use. Agroforestry Systems 45: $1-21$.

Ewel, J. J., M. J. Mazzarino, and C. W. Berish. 1991. Tropical soil fertility changes under monocultures and successional communities of different structure. Ecological Applications 1:289-302.

Fargione, J., C. S. Brown, and D. Tilman. 2003. Community assembly and invasion: an experimental test of neutral versus niche processes. Proceeding of the National Academy of Sciences USA 100:8916-8920.

Field, C. B. 1995. Productive capacity and biomass accumulation. Pages 402-406 in United Nations Environment Programme (UNEP), editor. Global biodiversity assessment. Cambridge University Press, Cambridge, UK.

Finkel, E. 1999. Australian biocontrol beats rabbits, but not rules. Science 285:1842.

Fischer, M., and J. Stöcklin. 1997. Local extinctions of plants in remnants of extensively used calcareous grasslands 1950-1985. Conservation Biology 11:727-737.

Fowler, N. 1986. The role of competition in plant communities in arid and semiarid regions. Annual Review of Ecology and Systematics 17:89-110.

Frank, D. A., and S. J. McNaughton. 1991. Stability increases with diversity in plant communities: empirical evidence from the 1988 Yellowstone drought. Oikos 62:360-362.

Freckleton, R. P., and A. R. Watkinson. 2000. On detecting and measuring competition in spatially structured plant communities. Ecology Letters 3:423-432.

Fridley, J. D. 2001. The influence of species diversity on ecosystem productivity: how, where and why? Oikos 93: 514-526.

Fridley, J. D. 2002. Resource availability dominates and alters the relationship between species diversity and ecosystem productivity in experimental plant communities. Oecologia 132:271-277.

Fridley, J. D. 2003. Diversity effects on production in different light and fertility environments: an experiment with communities of annual plants. Journal of Ecology 91:396406.

Frost, T. M., S. R. Carpenter, A. R. Ives, and T. K. Kratz. 1995. Species compensation and complementarity in ecosystem function. Pages 224-239 in C. G. Jones and J. H. Lawton, editors. Linking species and ecosystems. Chapman and Hall, San Diego, California, USA. 
Fukami, T., S. Naeem, and D. A. Wardle. 2001. On similarity among local communities in biodiversity experiments. Oikos 95:340-348.

Garnier, E., M.-L. Navas, M. P. Austin, J. M. Lilley, and R. M. Gifford. 1997. A problem for biodiversity-productivity studies: how to compare the productivity of multispecific plant mixtures to that of monocultures? Acta Oecologica 18:657-670.

Gaston, K. J., editor. 1996. Biodiversity. A biology of numbers and difference. Blackwell, Oxford, UK.

Gido, K. B., and J. H. Brown. 1999. Invasion of North American drainages by alien fish species. Freshwater Biology 42:387-399.

Giller, K. E., M. H. Beare, P. Lavelle, A. M. N. Izac, and M. J. Swift. 1997. Agricultural intensification, soil biodiversity and agroecosystem function. Applied Soil Ecology 6: 3-16.

Givnish, T. J. 1994. Does diversity beget stability? Nature 371:113-114

Gonzalez, A., J. H. Lawton, F. S. Gilbert, T. M. Blackburn, and I. Evans-Freke. 1998. Metapopulation dynamics, abundance, and distribution in a microecosystem. Science 281: 2045-2047.

Gordon, D. R. 1998. Effects of invasive, non-indigenous plant species on ecosystem processes: lessons from Florida. Ecological Applications 8:975-989.

Greenberg, R., P. Bichier, A. C. Angon, and R. Reitsma. 1997. Bird populations in shade and sun coffee plantations in central Guatemala. Conservation Biology 11:448-459.

Griffin, G. F., D. M. Stafford-Smith, S. R. Morton, G. E. Allan, K. A. Masters, and N. Preece. 1989. Status and implications of the invasion of tamarisk (Tamarix aphylla) on the Finke River, Northern Territory, Australia. Journal of Environmental Management 29:297-315.

Griffiths, B. S., K. Ritz, R. D. Bardgett, R. Cok, S. Christensen, F. Ekelund, S. J. Sorenson, E. Baath, J. Bloem, P. C. De Ruiter, J. Dolfing, and B. Nicolardot. 2000. Ecosystem response of pasture soil communities to fumigationinduced microbial diversity reductions: an examination of the biodiversity-ecosystem function relationship. Oikos 90: 279-294.

Grime, J. P. 1973a. Competitive exclusion in herbaceous vegetation. Nature 242:344-347.

Grime, J. P. 1973b. Control of species density in herbaceous vegetation. Journal of Environmental Management 1:153167.

Grime, J. P. 1979. Plant strategies and vegetation processes. John Wiley and Sons, Chichester, UK.

Grime, J. P. 1998. Benefits of plant diversity to ecosystems: immediate, filter and founder effects. Journal of Ecology 86:902-910.

Grime, J. P. 2001. Plant strategies, vegetation processes and ecosystem properties. John Wiley and Sons, Chichester, UK.

Grime, J. P., V. K. Brown, K. Thompson, G. J. Masters, S. H. Hillier, I. P. Clarke, A. P. Askew, D. Corker, and P. Kielty. 2000. The response of two contrasting limestone grasslands to simulated climate change. Science 289:762-765.

Grime, J. P., J. G. Hodgson, and R. Hunt. 1988. Comparative plant ecology: a functional approach to common British species. Unwyn Hyman, London, UK.

Grime, J. P., J. G. Hodgson, R. Hunt, K. Thompson, G. A. F. Hendrey, B. D. Campbell, A. Jalili, S. H. Hillier, S. Diaz, and M. J. W. Burke. 1997a. Functional types: testing the concept in Northern England. Pages 122-152 in T. M. Smith, H. H. Shugart, and F. I. Woodward, editors. Plant functional types: their relevance to ecosystem properties and global change. Cambridge University Press, Cambridge, UK.

Grime, J. P., et al. 1997b. Integrated screening validates primary axes of specialization in plants. Oikos 79:259-281.

Haggar, J. P., and J. J. Ewel. 1995. Establishment, resource acquisition, and early productivity as determined by biomass allocation patterns of three tropical tree species. Forest Science 41:689-708.

Haggar, J. P., and J. J. Ewel. 1997. Primary productivity and resource partitioning in model tropical ecosystems. Ecology 78:1211-1221.

Hanson, A. J., T. A. Spies, F. J. Swanson, and J. L. Ohmann. 1991. Conserving biodiversity in managed forests. BioScience 41:382-392.

Harper, J. L. 1977. Population biology of plants. Academic Press, London, UK

He, J.-S., F. A. Bazzaz, and B. Schmid. 2002. Interactive effects of diversity, nutrients and elevated $\mathrm{CO}_{2}$ on experimental plant communities. Oikos 97:337-348.

Hector, A. 1998. The effect of diversity on productivity: detecting the role of species complementarity. Oikos 82:597599.

Hector, A. 2002. Biodiversity and the functioning of grassland ecosystems: multi-site comparisons. Pages 71-95 in A. Kinzig, D. Tilman, and S. Pacala, editors. Functional consequences of biodiversity: experimental progress and theoretical extensions. Princeton University Press, Princeton, New Jersey, USA.

Hector, A., E. Bazeley-White, M. Loreau, S. Otway, and B. Schmid. 2002. Overyielding in plant communities: testing the sampling effect hypothesis with replicated biodiversity experiments. Ecology Letters 5:502-511.

Hector, A., A. Beale, A. Minns, S. Otway, and J. H. Lawton. $2000 a$. Consequences of loss of plant diversity for litter decomposition: mechanisms of litter quality and microenvironment. Oikos 90:357-371.

Hector, A., K. Dobson, A. Minns, E. Bazeley-White, and J. H. Lawton. 2001a. Community diversity and invasion resistance: an experimental test in a grassland ecosystem and a review of comparable studies. Ecological Research 16: 819-831.

Hector, A., J. Joshi, S. P. Lawler, E. Spehn, and A. Wilby. $2001 b$. Conservation implications of the link between biodiversity and ecosystem functioning. Oecologia 129:624628.

Hector, A., et al. 1999. Plant diversity and productivity experiments in European grasslands. Science 286:1123-1127.

Hector, A., et al. 2000b. No consistent effect of plant diversity on productivity? Response. Science 289:1255a.

Hiremath, A. J., and J. J. Ewel. 2001. Ecosystem nutrient use efficiency, productivity, and nutrient accrual in model tropical communities. Ecosystems 4:669-682.

Hobbie, S. E. 1992. Effects of plant species on nutrient cycling. Trends in Ecology and Evolution 7:336-339.

Hobbie, S. E., A. Shevtsova, and F. S. Chapin, III. 1999. Plant responses to species removal and experimental warming in Alaskan tussock tundra. Oikos 84:417-434.

Holling, C. S. 1986. Resilience of ecosystems: local surprise and global change. Pages 292-317 in W. C. Clark and R. E. Munn, editors. Sustainable development of the biosphere. Cambridge University Press, Cambridge, UK.

Holt, R. D., and M. Loreau. 2002. Biodiversity and ecosystem functioning: the role of trophic interactions and the importance of system openness. Pages 246-262 in A. P. Kinzig, S. W. Pacala, and D. Tilman, editors. The functional consequences of biodiversity: empirical progress and the- 
oretical extensions. Princeton University Press, Princeton, New Jersey, USA.

Hooper, D. U. 1998. The role of complementarity and competition in ecosystem responses to variation in plant diversity. Ecology 79:704-719.

Hooper, D. U., et al. 2000. Interactions between aboveground and belowground biodiversity in terrestrial ecosystems: patterns, mechanisms, and feedbacks. BioScience 50: $1049-1061$.

Hooper, D. U., and J. S. Dukes. 2004. Overyielding among plant functional groups in a long-term experiment. Ecology Letters 7:95-105.

Hooper, D., D. Hawksworth, and S. Dhillion. 1995. Microbial diversity and ecosystem processes. Pages 433-443 in United Nations Environment Programme (UNEP), editor. Global biodiversity assessment. Cambridge University Press, Cambridge, UK

Hooper, D. U., et al. 2002. Species diversity, functional diversity and ecosystem functioning. Pages 195-208 in M Loreau, S. Naeem, and P. Inchausti, editors. Biodiversity and ecosystem functioning: synthesis and perspectives. Oxford University Press, Oxford, UK.

Hooper, D. U., and P. M. Vitousek. 1997. The effects of plant composition and diversity on ecosystem processes. Science 277:1302-1305.

Hooper, D. U., and P. M. Vitousek. 1998. Effects of plant composition and diversity on nutrient cycling. Ecological Monographs 68:121-149.

Hughes, J. B., and J. Roughgarden. 1998. Aggregate community properties and the strength of species' interactions. Proceeding of the National Academy of Sciences USA 95 6837-6842.

Hulot, F. D., G. Lacroix, F. Lescher-Moutoue, and M. Loreau. 2000. Functional diversity governs ecosystem response to nutrient enrichment. Nature 405:340-344.

Hunter, M. D., and P. W. Price. 1992. Playing chutes and ladders: heterogeneity and the relative roles of bottom-up and top-down forces in natural communities. Ecology $\mathbf{7 3}$ 724-732.

Huston, M. 1979. A general hypothesis of species diversity. American Naturalist 113:81-101.

Huston, M. A. 1994. Biological diversity: the coexistence of species on changing landscapes. Cambridge University Press, Cambridge, UK.

Huston, M. A. 1997. Hidden treatments in ecological experiments: re-evaluating the ecosystem function of biodiversity. Oecologia 110:449-460.

Huston, M. A., L. W. Aarssen, M. P. Austin, B. S. Cade, J. D. Fridley, E. Garnier, J. P. Grime, J. Hodgson, W. K. Lauenroth, K. Thompson, J. H. Vandermeer, and D. A. Wardle. 2000. No consistent effect of plant diversity on productivity. Science 289:1255.

Huston, M. A., and A. C. McBride. 2002. Evaluating the relative strengths of biotic versus abiotic controls on ecosystem processes. Pages 47-60 in M. Loreau, S. Naeem, and P. Inchausti, editors. Biodiversity and ecosystem functioning: synthesis and perspectives. Oxford University Press, Oxford, UK.

Ingham, R. E., J. A. Trofymow, E. R. Ingham, and D. C. Coleman. 1985. Interactions of bacteria, fungi, and their nematode grazers: effects on nutrient cycling and plant growth. Ecological Monographs 55:119-140.

Ives, A. R., K. Gross, and J. L. Klug. 1999. Stability and variability in competitive communities. Science 286:542544.

Janssens, F., A. Peeters, J. R. B. Tallowin, J. P. Bakker, R. M. Bekker, F. Fillat, and M. J. M. Oomes. 1998. Relation- ship between soil chemical factors and grassland diversity. Plant and Soil 202:69-78.

Jenny, H. 1941. Factors of soil formation. McGraw-Hill, New York, New York, USA.

Jenny, H. 1980. Soil genesis with ecological perspectives. Springer-Verlag, New York, New York, USA.

Johnson, K. H. 2000. Trophic-dynamic considerations in relating species diversity to ecosystem resilience. Biological Reviews 75:347-376.

Jolliffe, P. A. 1997. Are mixed populations of plant species more productive than pure stands? Oikos 80:595-602.

Jones, C. G., and J. H. Lawton, editors. 1995. Linking species and ecosystems. Chapman and Hall, New York, New York, USA.

Jonsson, L., M. C. Nilsson, D. A. Wardle, and O. Zackrisson. 2001. Context dependent effects of ectomycorrhizal species richness on tree seedling productivity. Oikos 93:353364.

Joshi, J., et al. 2001. Local adaptation enhances performance of common plant species. Ecology Letters 4:536-544.

Kaiser, J. 1999. Stemming the tide of invading species. Science 285: 1836-1841.

Kenkel, N. C., D. A. Peltzer, D. Baluta, and D. Pirie. 2000. Increasing plant diversity does not influence productivity: empirical evidence and potential mechanisms. Community Ecology 1:165-170.

Kennedy, T. A., S. Naeem, K. M. Howe, J. M. H. Knops, D. Tilman, and P. Reich. 2002. Biodiversity as a barrier to ecological invasion. Nature 417:636-638.

Kinzig, A. P., S. W. Pacala, and D. Tilman, editors. 2002. The functional consequences of biodiversity: empirical progress and theoretical extensions. Princeton University Press, Princeton, New Jersey, USA.

Klironomos, J. N., J. McCune, M. Hart, and J. Neville. 2000. The influence of arbuscular mycorrhiza on the relationship between plant diversity and productivity. Ecology Letters 3:137-141.

Knops, J. M. H., D. Tilman, N. M. Haddad, S. Naeem, C. E. Mitchell, J. Haarstad, M. E. Ritchie, K. M. Howe, P. B. Reich, E. Siemann, and J. Groth. 1999. Effects of plant species richness on invasion dynamics, disease outbreaks, insect abundances and diversity. Ecology Letters 2:286293.

Korthals, G. W., P. Smilauer, C. Van Dijk, and W. H. Van der Putten. 2001. Linking above- and belowground diversity: abundance and trophic complexity in soil as a response to experimental plant communities on abandoned arable land. Functional Ecology 16:506-514.

Kunin, W. E., and J. H. Lawton. 1996. Does biodiversity matter? Evaluating the case for conserving species. Pages 283-308 in K. Gaston, editor. Biodiversity: a biology of numbers and differences. Blackwell Science, Oxford, UK.

Laakso, J., and H. Setälä. 1999. Sensitivity of primary production to changes in the architecture of belowground food webs. Oikos 87:57-64.

Landsberg, J. 1999. Response and effect: different reasons for classifying plant functional types under grazing. Pages 911-915 in D. Eldridge and D. Freudenberger, editors. People and rangelands: building the future. Proceedings of the VI International Rangeland Congress. VI International Rangeland Congress, Townsville, Australia.

Lauck, T., C. W. Clark, M. Mangel, and G. R. Munro. 1998. Implementing the precautionary principle in fisheries management through marine reserves. Ecological Applications 8:S72-S78.

Lavorel, S. 1999. Ecological diversity and resilience of Mediterranean vegetation to disturbance. Diversity and Distributions 5:1-2. 
Lavorel, S., and E. Garnier. 2001. Aardvarck to Zyzyxia: functional groups across kingdoms. New Phytologist 149:360364.

Lavorel, S., and E. Garnier. 2002. Predicting the effects of environmental changes on plant community composition and ecosystem functioning: revisiting the Holy Grail. Functional Ecology 16:545-556.

Lavorel, S., S. McIntyre, J. Landsberg, and T. D. A. Forbes. 1997. Plant functional classifications: from general groups to specific groups based on response to disturbance. Trends in Ecology and Evolution 12:474-478.

Lawton, J. H. 1994. What do species do in ecosystems? Oikos 71:367-374.

Lawton, J. H., and V. K. Brown. 1993. Redundancy in ecosystems. Pages 255-270 in E.-D. Schulze and H. A. Mooney, editors. Biodiversity and ecosystem function. Springer-Verlag, Berlin, Germany.

Lehman, C. L., and D. Tilman. 2000. Biodiversity, stability, and productivity in competitive communities. American Naturalist 156:534-552.

Lehman, J. T., D. B. Botkin, and G. E. Likens. 1975. The assumptions and rationales of a computer model of phytoplankton population dynamics. Limnology and Oceanography 20:343-364.

Leibold, M. A. 1995. The niche concept revisited: mechanistic models and community context. Ecology 76:13711382.

Lepš, J., et al. 2001. Separating the chance effect from the other diversity effects in the functioning of plant communities. Oikos 92:123-134.

Lepš, J., J. Osbornova-Kosinoa, and K. Rejmanek. 1982. Community stability, complexity and species life-history strategies. Vegetatio 511:53-63.

Levine, J. M. 2000. Species diversity and biological invasions: relating local process to community pattern. Science 288: $852-854$

Levine, J. M., and C. M. D'Antonio. 1999. Elton revisited: a review of evidence linking diversity and invasibility. Oikos 87:15-26.

Levine, J. M., M. Vilà, C. M. D'Antonio, J. S. Dukes, K. Grigulis, and S. Lavorel. 2003. Mechanisms underlying the impacts of exotic plant invasions. Proceedings of the Royal Society of London, Series B 270:775-781.

Liiri, M., H. Setälä, J. Haimi, T. Pennanen, and H. Fritze. 2002. Relationship between soil microarthropod species diversity and plant growth does not change when the system is disturbed. Oikos 96:137-149.

Lodge, D. M., C. A. Taylor, D. M. Holdich, and J. Skurdal. 2000. Nonindigenous crayfishes threaten North American freshwater biodiversity: lessons from Europe. Fisheries 25: $7-20$.

Loreau, M. 1998a. Biodiversity and ecosystem functioning: a mechanistic model. Proceedings of the National Academy of Sciences (USA) 95:5632-5636.

Loreau, M. 1998b. Separating sampling and other effects in biodiversity experiments. Oikos 82:600-602.

Loreau, M. 2000. Biodiversity and ecosystem functioning: recent theoretical advances. Oikos 91:3-17.

Loreau, M. 2001. Microbial diversity, producer-decomposer interactions and ecosystem processes: a theoretical model. Proceedings of the Royal Society of London, Series B 268: 303-309.

Loreau, M., A. Downing, M. C. Emmerson, A. Gonzalez, J. Hughes, P. Inchausti, J. Joshi, J. Norberg, and O. Sala. 2002a. A new look at the relationship between diversity and stability. Pages 79-91 in M. Loreau, S. Naeem, and P. Inchausti, editors. Biodiversity and ecosystem functioning: synthesis and perspectives. Oxford University Press, Oxford, UK.

Loreau, M., and A. Hector. 2001. Partitioning selection and complementarity in biodiversity experiments. Nature $\mathbf{4 1 2}$ : 72-76.

Loreau, M., S. Naeem, and P. Inchausti, editors. 2002b. Biodiversity and ecosystem functioning: synthesis and perspectives. Oxford University Press, Oxford, UK.

Loreau, M., S. Naeem, P. Inchausti, J. Bengtsson, J. P. Grime, A. Hector, D. U. Hooper, M. A. Huston, D. Raffaelli, B. Schmid, D. Tilman, and D. A. Wardle. 2001. Biodiversity and ecosystem functioning: current knowledge and future challenges. Science 294:804-808.

Lubchenco, J., et al. 1991. The sustainable biosphere initiative: an ecological research agenda. Ecology 72:371-412.

Lyons, K. G., and M. W. Schwartz. 2001. Rare species loss alters ecosystem function: invasion resistance. Ecology Letters 4:358-365.

MacArthur, R. H. 1955. Fluctuations of animal populations and a measure of community stability. Ecology 36:533536.

MacGillivray, C. W., J. P. Grime, and The Integrated Screening Programme Team. 1995. Testing predictions of the resistance and resilience of vegetation subjected to extreme events. Functional Ecology 9:640-649.

Mäder, P., and A. Fliessbach. 2002. Soil fertility and biodiversity in organic farming. Science 296:1694-1697.

Malakoff, D. 1999. Fighting fire with fire. Science 285:18411843.

May, R. M. 1974. Stability and complexity in model ecosystems. Princeton University Press, Princeton, New Jersey, USA.

McCann, K. S. 2000. The diversity-stability debate. Nature 405:228-233.

McGrady-Steed, J., P. M. Harris, and P. J. Morin. 1997. Biodiversity regulates ecosystem predictability. Nature 390: 162-165.

McKane, R. B., L. C. Johnson, G. R. Shaver, K. J. Nadelhoffer, E. B. Rastetter, B. Fry, A. E. Giblin, K. Kielland, B. L. Kwiatkowski, J. A. Laundre, and G. Murray. 2002. Resource-based niches provide a basis for plant species diversity and dominance in arctic tundra. Nature 415:6871.

McNaughton, S. J. 1977. Diversity and stability of ecological communities: a comment on the role of empiricism in ecology. American Naturalist 111:515-525.

McNaughton, S. J. 1985. Ecology of a grazing ecosystem: the Serengeti. Ecological Monographs 55:259-294.

McNaughton, S. J. 1993. Biodiversity and function of grazing ecosystems. Pages 361-383 in E.-D. Schulze and H. A. Mooney, editors. Biodiversity and ecosystem function. Springer-Verlag, Berlin, Germany.

Mikola, J., R. D. Bardgett, and K. Hedlund. 2002. Biodiversity, ecosystem functioning, and soil decomposer food webs. Pages 169-180 in M. Loreau, S. Naeem, and P. Inchausti, editors. Biodiversity and ecosystem functioning: synthesis and perspectives. Oxford University Press, Oxford, UK.

Mikola, J., and H. Setälä. 1998a. No evidence of trophic cascades in an experimental microbial-based soil food web. Ecology 79:153-164.

Mikola, J., and H. Setälä. 1998b. Relating species diversity to ecosystem functioning: mechanistic backgrounds and experimental approach with a decomposer food web. Oikos 83:180-194.

Minns, A., J. Finn, A. Hector, M. Caldeira, J. Joshi, C. Palmborg, B. Schmid, M. Scherer-Lorenzen, E. Spehn, A. 
Troumbis, and the BIODEPTH Project. 2001. The functioning of European grassland ecosystems: potential benefits of biodiversity to agriculture. Outlook on Agriculture 30: $179-185$.

Mittelbach, G., S. M. Scheiner, and C. F. Steiner. 2003. What is the observed relationship between species richness and productivity? Reply. Ecology 84:3390-3395.

Mittelbach, G. G., C. F. Steiner, S. M. Scheiner, K. L. Gross, H. L. Reynolds, R. B. Waide, M. R. Willig, S. I. Dodson, and L. Gough. 2001. What is the observed relationship between species richness and productivity? Ecology 82: 2381-2396.

Mooney, H. A. 2002. The debate on the role of biodiversity in ecosystem functioning. Pages 12-17 in M. Loreau, S. Naeem, and P. Inchausti, editors. Biodiversity and ecosystem functioning. Oxford University Press, Oxford, UK.

Mooney, H. A., and J. A. Drake, editors. 1986. Ecology of biological invasions of North America and Hawaii. Springer-Verlag, New York, New York, USA.

Morin, P. J., and J. McGrady-Steed. 2004. Biodiversity and ecosystem functioning in aquatic microbial systems: a new analysis of temporal variation and species richness-predictability relations. Oikos 104:458-466.

Mouquet, N., J. L. Moore, and M. Loreau. 2002. Plant species richness and community productivity: why the mechanism that promotes coexistence matters. Ecology Letters 5:5665.

Mulder, C. P. H., A. Jumpponen, P. Högberg, and K. HussDanell. 2002. How plant diversity and legumes affect nitrogen dynamics in experimental grassland communities. Oecologia 133:412-421.

Mulder, C. P. H., J. Koricheva, K. Huss-Danell, P. Högberg, and J. Joshi. 1999. Insects affect relationships between plant species richness and ecosystem processes. Ecology Letters 2:237-246.

Mulder, C. P. H., D. D. Uliassi, and D. F. Doak. 2001. Physical stress and diversity-productivity relationships: the role of positive species interactions. Proceedings of the National Academy of Sciences (USA) 98:6704-6708.

Muller, P. E. 1884. Studier over skovjord, som bidrag til skovdyrkningens theori. II Om muld og mor i egeskove og paa heder. Tidsskrift for Skovbrug 7:232.

Nabhan, G. P., and S. L. Buchmann. 1997. Services provided by pollinators. Pages $133-150$ in G. Daily, editor. Nature's services: societal dependence on natural ecosystems. Island Press, Washington, D.C., USA.

Naeem, S. 1998. Species redundancy and ecosystem reliability. Conservation Biology 12:39-45.

Naeem, S. 2001. Experimental validity and ecological scale as tools for evaluating research programs. Pages 223-250 in R. H. Gardner, W. M. Kemp, V. S. Kennedy, and J. E. Petersen, editors. Scaling relationships in experimental ecology. Columbia University Press, New York, New York, USA.

Naeem, S. 2002a. Disentangling the impacts of diversity on ecosystem functioning in combinatorial experiments. Ecology 83:2925-2935.

Naeem, S. 2002b. Ecosystem consequences of biodiversity loss: the evolution of a paradigm. Ecology 83:1537-1552.

Naeem, S., D. R. Hahn, and G. Schuurman. 2000a. Producerdecomposer co-dependency influences biodiversity effects. Nature 403:762-764.

Naeem, S., J. M. H. Knops, D. Tilman, K. M. Howe, T. Kennedy, and S. Gale. 2000b. Plant diversity increases resistance to invasion in the absence of covarying extrinsic factors. Oikos 91:97-108.
Naeem, S., and S. Li. 1997. Biodiversity enhances ecosystem reliability. Nature 390:507-509.

Naeem, S., L. J. Thompson, S. P. Lawler, J. H. Lawton, and R. M. Woodfin. 1994. Declining biodiversity can alter the performance of ecosystems. Nature 368:734-737.

Naeem, S., L. J. Thompson, S. P. Lawler, J. H. Lawton, and R. M. Woodfin. 1995. Empirical evidence that declining species diversity may alter the performance of terrestrial ecosystems. Philosophical Transactions of the Royal Society of London B 347:249-262.

Naylor, R. L., and P. R. Ehrlich. 1997. Natural pest control services and agriculture. Pages 151-174 in G. Daily, editor. Nature's services: societal dependence on natural ecosystems. Island Press, Washington, D.C., USA.

Nijs, I., and I. Impens. 2000. Underlying effects of resource use efficiency in diversity-productivity relationships. Oikos 91:204-208.

Nijs, I., and J. Roy. 2000. How important are species richness, species evenness and interspecific differences to productivity? A mathematical model. Oikos 88:57-66.

Niklaus, P. A., E. Kandeler, P. W. Leadley, B. Schmid, D. Tscherko, and C. Körner. 2001a. A link between plant diversity, elevated $\mathrm{CO}_{2}$ and soil nitrate. Oecologia 127: 540-548.

Niklaus, P. A., P. W. Leadley, B. Schmid, and C. Körner. $2001 b$. A long-term study on biodiversity $\times$ elevated $\mathrm{CO}_{2}$ interactions in grassland. Ecological Monographs 71:341356.

Noble, I. R., and I. C. Burke. 1995. Biodiversity and ecosystem functioning: ecosystem analyses. Section 6.2.5: the influence of biodiversity on landscape structure. Pages 422-427 in United Nations Environment Programme (UNEP), editor. Global biodiversity assessment. Cambridge University Press, Cambridge, UK.

Norberg, J. 1999. Linking nature's services to ecosystems: some general ecological concepts. Ecological Economics 29:183-202.

Norberg, J. 2000. Resource-niche complementarity and autotrophic compensation determines ecosystem-level responses to increased cladoceran species richness. Oecologia 122:264-272.

Ong, C. K., and C. R. Black. 1994. Complementarity of resource use in intercropping and agroforestry systems. Pages 255-278 in J. L. Monteith, R. K. Scott, and M. H. Unswerth, editors. Resource capture by crops. Proceedings of 52nd University of Nottingham Easter School. Nottingham University Press, Loughborough, UK.

Ong, C., and P. Huxley, editors. 1997. Tree-crop interactions: a physiological approach. CAB International, Wallingford, UK.

Ostfeld, R. S., and F. Keesing. 2000. The function of biodiversity in the ecology of vector-borne zoonotic diseases. Canadian Journal of Zoology 78:2061-2078.

Pacala, S. W., and D. H. Deutschman. 1995. Details that matter: the spatial distribution of individual trees maintains forest ecosystem function. Oikos 74:357-365.

Paine, R. T. 2002. Trophic control of production in a rocky intertidal community. Science 296:736-739.

Pearson, T. H., and R. Rosenberg. 1978. Macrobenthic succession in relation to organic enrichment and pollution of the marine environment. Oceanography and Marine Biology: An Annual Review 16:229-311.

Perfecto, I., R. Rice, R. Greenberg, and M. V. d. Voolt. 1996. Shade coffee as refuge of biodiversity. BioScience 46:598608.

Petchey, O. L. 2000. Species diversity, species extinction, and ecosystem function. American Naturalist 155:696-702. 
Petchey, O. L. 2002. Functional diversity (FD), species richness and community composition. Ecology Letters 5:402411.

Petchey, O. L. 2003. Integrating methods that investigate how complementarity influences ecosystem functioning. Oikos 101:323-330.

Petchey, O. L., P. T. McPhearson, T. M. Casey, and P. J. Morin. 1999. Environmental warming alters food-web structure and ecosystem function. Nature 402:69-72.

Peterson, G., C. R. Allen, and C. S. Holling. 1998. Ecological resilience, biodiversity and scale. Ecosystems 1:6-18.

Pfisterer, A. B., J. Joshi, B. Schmid, and M. Fischer. 2004. Rapid decay of diversity-productivity relationships after invasion in experimental plant communities. Basic and Applied Ecology 5:5-14.

Pfisterer, A. B., and B. Schmid. 2002. Diversity-dependent production can decrease the stability of ecosystem functioning. Nature 416:84-86.

Pimentel, D., U. Stachow, D. A. Takacs, H. W. Brubaker, A. R. Dumas, J. J. Meaney, J. A. S. O’Neil, D. E. Onsi, and D. B. Corzilius. 1992. Conserving biological diversity in agricultural/forestry systems. BioScience 42:354-362.

Pimm, S. L. 1984. The complexity and stability of ecosystems. Nature 307:321-326.

Planty-Tabacchi, A.-M., E. Tabacchi, R. J. Naiman, C. Deferrari, and H. Décamps. 1996. Invasibility of species-rich communities in riparian zones. Conservation Biology 10: 598-607.

Polley, H. W., B. J. Wilsey, and J. D. Derner. 2003. Do species evenness and plant density influence the magnitude of selection and complementarity effects in annual plant species mixtures? Ecology Letters 6:248-256.

Postel, S. 1999. Pillar of sand: can the irrigation miracle last? W. W. Norton, New York, New York, USA.

Power, M. E., D. Tilman, J. A. Estes, B. A. Menge, W. J. Bond, L. S. Mills, G. Daily, J. C. Castilla, J. Lubchenco, and R. T. Paine. 1996. Challenges in the quest for keystones. BioScience 46:609-620.

Prieur-Richard, A.-H., and S. Lavorel. 2000. Invasions: the perspective of diverse plant communities-a review. Australian Ecology 25:1-7.

Prieur-Richard, A.-H., S. Lavorel, A. Dos Santos, and K. Grigulis. 2002a. Mechanisms of resistance of Mediterranean annual communities to invasion by Conyza bonariensis: effects of native functional composition. Oikos 99:338346.

Prieur-Richard, A.-H., S. Lavorel, Y. B. Linhart, and A. Dos Santos. 2002 b. Plant diversity, herbivory and resistance of a plant community to invasion in Mediterranean annual communities. Oecologia 130:96-104.

Purvis, A., and A. Hector. 2000. Getting the measure of biodiversity. Nature 405:212-219.

Raffaelli, D., W. H. v. d. Putten, L. Persson, D. A. Wardle, O. L. Petchey, J. Koricheva, M. G. A. v. d. Heijden, J. Mikola, and T. Kennedy. 2002. Multi-trophic dynamics and ecosystem processes. Pages 147-154 in M. Loreau, S. Naeem, and P. Inchausti, editors. Biodiversity and ecosystem functioning: synthesis and perspectives. Oxford University Press, Oxford, UK.

Ratcliffe, D. A. 1984. Post medieval and recent changes in British vegetation: the culmination of human influence. New Phytologist 98:73-100.

Reich, P. B., et al. 2001. Plant diversity enhances ecosystem responses to elevated $\mathrm{CO}_{2}$ and nitrogen deposition. Nature 410:809-812.

Root, R. B. 1967. The niche exploitation pattern of the Bluegray Gnatcatcher. Ecological Monographs 37:317-350.
Rosenzweig, M. L., and Z. Abramsky. 1993. How are diversity and productivity related? Pages $52-65$ in R. E. Ricklefs and D. Schulter, editors. Species diversity in ecological communities: historical and geographical perspectives. University of Chicago Press, Chicago, Illinois, USA.

Ruesink, J. L., and D. S. Srivastava. 2001. Numerical and per capita responses to species loss: mechanisms maintaining ecosystem function in a community of stream insect detrivores. Oikos 93:221-234.

Sala, O. E., et al. 2000. Global biodiversity scenarios for the year 2100. Science 287:1770-1774.

Sala, O. E., R. A. Golluscio, W. K. Lauenroth, and A. Soriano. 1989. Resource partitioning between shrubs and grasses in the Patagonian steppe. Oecologia 81:501-505.

Sala, O. E., W. K. Lauenroth, S. J. McNaughton, G. Rusch, and X. Zhang. 1996. Biodiversity and ecosystem function in grasslands. Pages 129-149 in H. A. Mooney, J. H. Cushman, E. Medina, O. E. Sala, and E.-D. Schulze, editors. Functional roles of biodiversity: a global perspective. John Wiley, Chichester, UK.

Sankaran, M., and S. J. McNaughton. 1999. Determinants of biodiversity regulate compositional stability of communities. Nature 401:691-693.

Sax, D. F., and J. H. Brown. 2000. The paradox of invasion. Global Ecology and Biogeography 9:363-371.

Sax, D. F., and S. D. Gaines. 2003. Species diversity: from global decreases to local increases. Trends in Ecology and Evolution 18:561-566.

Schenk, H. J., and R. B. Jackson. 2002. Rooting depths, lateral root spreads and belowground/aboveground allometries of plants in water-limited ecosystems. Journal of Ecology 90:480-494.

Schindler, D. E., S. R. Carpenter, J. J. Cole, J. F. Kitchell, and M. L. Pace. 1997. Influence of food web structure on carbon exchange between lakes and the atmosphere. Science 277:248-251.

Schindler, D. W., M. A. Turner, M. P. Stainton, and G. A. Linsey. 1986. Natural sources of acid neutralizing capacity in low alkalinity lakes of the Precambrian shield. Science 232:844-847.

Schläpfer, F., and J. D. Erikson. 2001. A biotic control perspective on nitrate contamination of groundwater from agricultural production. Agriculture and Resource Economics Review 30:113-126.

Schläpfer, F., M. Tucker, and I. Seidl. 2002. Returns from hay cultivation in fertilized low diversity and non-fertilized high diversity grassland. Environmental and Resource Economics 21:89-100.

Schmid, B. 2002. The species richness-productivity controversy. Trends in Ecology and Evolution 17:113-114.

Schmid, B., A. Hector, M. A. Huston, P. Inchausti, I. Nijs, P. W. Leadley, and D. Tilman. 2002a. The design and analysis of biodiversity experiments. Pages 61-75 in M. Loreau, S. Naeem, and P. Inchausti, editors. Biodiversity and ecosystem functioning. Oxford University Press, Oxford, UK.

Schmid, B., J. Joshi, and F. Schläpfer. 2002b. Empirical evidence for biodiversity-ecosystem functioning relationships. Pages 120-150 in A. Kinzig, D. Tilman, and S. Pacala, editors. Functional consequences of biodiversity: experimental progress and theoretical extensions. Princeton University Press, Princeton, New Jersey, USA.

Schmid, B., and A. B. Pfisterer. 2003. Species vs. community perspectives in biodiversity experiments. Oikos 100:620621.

Schmid, K. A., and R. S. Ostfeld. 2001. Biodiversity and the dilution effect in disease ecology. Ecology 82:609-619. 
Schulze, E. D., and H. A. Mooney, editors. 1993. Biodiversity and ecosystem function. Springer-Verlag, Berlin, Germany.

Schwartz, M. W., C. A. Brigham, J. D. Hoeksema, K. G. Lyons, M. H. Mills, and P. J. van Mantgem. 2000. Linking biodiversity to ecosystem function: implications for conservation ecology. Oecologia 122:297-305.

Scurlock, J. M., K. Johnson, and R. J. Olson. 2002. Estimating net primary productivity from grassland biomass dynamics measurements. Global Change Biology 8:736753.

Shea, K., and P. Chesson. 2002. Community ecology theory as a framework for biological invasions. Trends in Ecology and Evolution 17:170-176.

Silver, W. L., S. Brown, F. N. Scatena, and J. J. Ewel. 2001. Managed ecosystems deserve greater attention. Bulletin of the Ecological Society of America 82:91-93.

Simberloff, D., and T. Dayan. 1991. The guild concept and the structure of ecological communities. Annual Review of Ecology and Systematics 22:115-143.

Smith, T. M., H. H. Shugart, and F. I. Woodward, editors. 1997. Plant functional types: their relevance to ecosystem properties and global change. Cambridge University Press, Cambridge, UK.

Sousa, W. P. 1979. Experimental investigation of disturbance and ecological succession in a rocky intertidal algal community. Ecological Monographs 49:227-254.

Špaèková, I., and J. Lepš. 2001. Procedure for separating the selection effect from other effects in diversity-productivity relationships. Ecology Letters 4:585-594.

Spehn, E. M., J. Joshi, B. Schmid, M. Diemer, and C. Körner 2000. Above-ground resource use increases with plant species richness in experimental grassland ecosystems. Functional Ecology 14:326-337.

Spehn, E. M., et al. 2002. The role of legumes as a component of biodiversity in a cross-European study of grassland biomass nitrogen. Oikos 98:205-218.

Stachowicz, J. J., R. B. Whitlatch, and R. Osman. 1999. Species diversity and invasion resistance in a marine ecosystem. Science 286:1577-1579.

Steffen, W. L. 1996. A periodic-table for ecology: a chemists view of plant functional types. Journal of Vegetation Science 7:425-430.

Steiner, K. 1982. Intercropping in tropical smallholder agriculture with special reference to West Africa. German Agency for Technical Cooperation (GTZ), Eschborn, Germany.

Stephan, A., A. H. Meyer, and B. Schmid. 2000. Plant diversity positively affects soil bacterial diversity in experimental grassland ecosystems. Journal of Ecology 88:988998.

Stevens, M. H. H., and W. P. Carson. 2001. Phenological complementarity, species diversity, and ecosystem function. Oikos 92:291-296.

Stocker, R., C. Körner, B. Schmid, P. A. Niklaus, and P. W. Leadley. 1999. A field study of the effects of elevated $\mathrm{CO}_{2}$ and plant species diversity on ecosystem-level gas exchange in a planted calcareous grassland. Global Change Biology 5:95-105.

Stöcklin, J., and M. Fischer. 1999. Plants with longer-lived seeds have lower local extinction rates in grassland remnants 1950-1985. Oecologia 120:539-543.

Stohlgren, T. J., D. Binkley, G. W. Chong, M. A. Kalkhan, L. D. Scheli, K. A. Bull, Y. Otsuki, G. Newman, M. Bashkin, and Y. Son. 1999. Exotic plant species invade hot spots of native plant diversity. Ecological Monographs 69:2546 .
Stokstad, E. 1999. Vanquishing nutria: where there's a will, there's a way. Science 285:1838.

Stoll, P., and D. Prati. 2001. Intraspecific aggregation alters competitive interactions in experimental plant communities. Ecology 82:319-327.

Stone, R. 1999. Keeping paradise safe for the natives. Science 285: 1837.

Strong, D. R. 1992. Are trophic cascades all wet? Differentiation and donor-control in speciose ecosystems. Ecology 73:747-754.

Suding, K. N., D. E. Goldberg, and K. M. Hartman. 2003. Relationships among species traits: separating levels of response and identifying linkages to abundance. Ecology 84: $1-16$.

Swift, M. J., and J. M. Anderson. 1993. Biodiversity and ecosystem function in agricultural systems. Pages 15-41 in E.-D. Schulze and H. A. Mooney, editors. Biodiversity and ecosystem function. Springer-Verlag, Berlin, Germany.

Symstad, A. J. 2000. A test of the effects of functional group richness and composition on grassland invasibility. Ecology 81:99-109.

Symstad, A. J., and D. Tilman. 2001. Diversity loss, recruitment limitation, and ecoystem functioning: lessons learned from a removal experiment. Oikos 92:424-435.

Symstad, A. J., D. Tilman, J. Willson, and J. M. H. Knops. 1998. Species loss and ecosystem functioning: effects of species identity and community composition. Oikos 81: 389-397.

Thébault, E., and M. Loreau. 2003. Food-web constraints on biodiversity-ecosystem functioning relationships. Proceeding of the National Academy of Sciences USA 100:1494914954.

Thompson, J., et al. 2001. Frontiers in ecology. BioScience 51:15-24.

Thompson, K. 1994. Predicting the fate of temperate species in response to human disturbance and global change. Pages 61-76 in T. J. B. Boyle and C. E. B. Boyle, editors. Biodiversity, temperate ecosystems and global change. Springer-Verlag, Berlin, Germany.

Tilman, D. 1987. Secondary succession and the pattern of plant dominance along experimental nitrogen gradients. Ecological Monographs 57:189-214.

Tilman, D. 1988. Plant strategies and the dynamics and structure of plant communities. Princeton University Press, Princeton, New Jersey, USA.

Tilman, D. 1996. Biodiversity: population versus ecosystem stability. Ecology 77:350-363.

Tilman, D. 1997a. Community invasibility, recruitment limitation, and grassland biodiversity. Ecology 78:81-92.

Tilman, D. 1997b. Distinguishing between the effects of species diversity and species composition. Oikos 80:185.

Tilman, D. 1999. The ecological consequences of changes in biodiversity: a search for general principles. Ecology 80: 1455-1474.

Tilman, D. 2001. Effects of diversity and composition on grassland stability and productivity. Pages 183-207 in M. C. Press, N. J. Huntley, and S. Levin, editors. Ecology: achievement and challenge. Blackwell Science, Oxford, UK.

Tilman, D., and J. A. Downing. 1994. Biodiversity and stability in grasslands. Nature 367:363-365.

Tilman, D., J. A. Downing, and D. A. Wedin. 1994. Does diversity beget stability? Reply. Nature 371:114.

Tilman, D., J. Knops, D. Wedin, and P. Reich. 2002. Experimental and observational studies of diversity, productivity, and stability. Pages 42-70 in A. Kinzig, S. Pacala, and D. Tilman, editors. Functional consequences of biodiversity: 
empirical progress and theoretical extensions. Princeton University Press, Princeton, New Jersey, USA.

Tilman, D., J. Knops, D. Wedin, P. Reich, M. Ritchie, and E. Siemann. 1997a. The influence of functional diversity and composition on ecosystem processes. Science 277:13001302.

Tilman, D., C. L. Lehman, and C. E. Bristow. 1998. Diversity-stability relationships: statistical inevitability or ecological consequence? American Naturalist 151:277-282.

Tilman, D., C. L. Lehman, and K. T. Thomson. 1997b. Plant diversity and ecosystem productivity: theoretical considerations. Proceedings of the National Academy of Sciences (USA) 94:1857-1861.

Tilman, D., P. B. Reich, J. Knops, D. Wedin, T. Mielke, and C. Lehman. 2001. Diversity and productivity in a longterm grassland experiment. Science 294:843-845.

Tilman, D., D. Wedin, and J. Knops. 1996. Productivity and sustainability influenced by biodiversity in grassland ecosystems. Nature 379:718-720.

Trenbath, B. R. 1974. Biomass productivity of mixtures. Advances in Agronomy 26:177-210.

Trenbath, B. R. 1999. Multispecies cropping systems in India. Pages 381-405 in E. C. Lefroy, R. J. Hobbs, M. H. O'Connor, and J. S. Pate, editors. Agriculture as a mimic of natural systems. Kluwer Academic, Dortrecht, The Netherlands.

Troumbis, A. Y., P. G. Dimitrakopoulos, A. S. Siamantziouras, and D. Memtsas. 2000. Hidden diversity and productivity patterns in mixed Mediterranean grasslands. Oikos 90:549559.

Troumbis, A. Y., and D. Memtsas. 2000. Observational evidence that diversity may increase productivity in Mediterranean shrublands. Oecologia 125:101-108.

Valiela, I., G. Tomasky, J. Hauxwell, M. L. Cole, J. Cebrián, and K. D. Kroeger. 2000. Operationalizing sustainability: management and risk assessment of land-derived nitrogen loads to estuaries. Ecological Applications 10:1006-1023.

Van Cleve, K., F. S. Chapin, III, C. T. Dryness, and L. A. Vireck. 1991. Element cycling in taiga forest: state-factor control. BioScience 41:78-88.

van der Heijden, M. G. A., J. N. Klironomos, M. Ursic, P. Moutoglis, R. Streitwolf-Engel, T. Boller, A. Wiemken, and I. R. Sanders. 1998. Mycorrhizal fungal diversity determines plant biodiversity, ecosystem variability and productivity. Nature 396:69-72.

van der Heijden, M. G. A., J. N. Klironomos, M. Ursic, P. Moutoglis, R. Streitwolf-Engel, T. Boller, A. Wiemken, and I. R. Sanders. 1999. "Sampling effect", a problem in biodiversity manipulation? A reply to David A. Wardle. Oikos 87:408-410.

Vandermeer, J. H. 1989. The ecology of intercropping. Cambridge University Press, Cambridge, UK.

Vandermeer, J. H. 1990. Intercropping. Pages 481-516 in C. R. Carrol, J. H. Vandermeer, and P. M. Rosset, editors. Agroecology. McGraw Hill, New York, New York, USA.

Vandermeer, J., and R. Carvajal. 2001. Metapopulation dynamics and the quality of the matrix. American Naturalist 158:211-220.

Vandermeer, J., D. Lawrence, A. Symstad, and S. Hobbie. 2002. Effect of biodiversity on ecosystem functioning in managed ecosystems. Pages 209-220 in M. Loreau, S. Naeem, and P. Inchausti, editors. Biodiversity and ecosystem functioning: synthesis and perspectives. Oxford University Press, Oxford, UK.

Vandermeer, J., M. van Noordwijk, J. Anderson, C. Ong, and I. Perfecto. 1998. Global change and multi-species agroe- cosystems: concepts and issues. Agriculture, Ecosystems and Environment 67:1-22.

Van der Putten, W. H., et al. 2000. Plant species diversity as a driver of early succession in abandoned fields: a multisite approach. Oecologia 124:91-99.

Vander Zanden, M. J., J. M. Casselman, and J. B. Rasmussen. 1999. Stable isotope evidence for the food web consequences of species invasions in lakes. Nature 401:464-467. van Ruijven, J., and F. Berendse. 2003. Positive effects of plant species diversity on productivity in the absence of legumes. Ecology Letters 6:170-175.

Vitousek, P. M. 1986. Biological invasions and ecosystem properties: can species make a difference? Pages 163-176 in H. A. Mooney and J. A. Drake, editors. Ecology of biological invasions of North America and Hawaii. Springer-Verlag, New York, New York, USA.

Vitousek, P. M. 1990. Biological invasions and ecosystem processes: towards an integration of population biology and ecosystem studies. Oikos 57:7-13.

Vitousek, P. M., and D. U. Hooper. 1993. Biological diversity and terrestrial ecosystem biogeochemistry. Pages 3-14 in E.-D. Schulze and H. A. Mooney, editors. Biodiversity and ecosystem function. Springer-Verlag, Berlin, Germany.

Vitousek, P. M., and L. R. Walker. 1989. Biological invasion by Myrica faya in Hawai'i: plant demography, nitrogen fixation, ecosystem effects. Ecological Monographs 59: 247-265.

Waide, R. B., M. R. Willig, C. F. Steiner, G. Mittelbach, L. Gough, S. I. Dodson, G. P. Juday, and R. Parmenter. 1999. The relationship between productivity and species richness. Annual Review of Ecology and Systematics 30:257-300.

Walker, B. H. 1992. Biodiversity and ecological redundancy. Conservation Biology 6:18-23.

Walker, B., A. Kinzig, and J. Langridge. 1999. Plant attribute diversity, resilience, and ecosystem function: the nature and significance of dominant and minor species. Ecosystems 2: 95-113.

Wardle, D. A. 1998. A more reliable design for biodiversity study? Nature 394:30.

Wardle, D. A. 1999. Is "sampling effect" a problem for experiments investigating biodiversity-ecosystem function relationships? Oikos 87:403-407.

Wardle, D. A. 2001a. Experimental demonstration that plant diversity reduces invasibility: evidence of a biological mechanism or a consequence of sampling effect? Oikos 95: 161-170.

Wardle, D. A. 2001b. No observational evidence for diversity enhancing productivity in Mediterranean shrublands. Oecologia 129:620-621.

Wardle, D. A. 2002. Communities and ecosystems: linking the aboveground and belowground components. Princeton University Press, Princeton, New Jersey, USA.

Wardle, D. A., K. I. Bonner, and G. M. Barker. 2000a. Stability of ecosystem properties in response to above-ground functional group richness and composition. Oikos 89:1123.

Wardle, D. A., K. I. Bonner, G. M. Barker, G. W. Yeates, K. S. Nicholson, R. D. Bardgett, R. N. Watson, and A. Ghani. 1999. Plant removals in perennial grassland: vegetation dynamics, decomposers, soil biodiversity, and ecosystem properties. Ecological Monographs 69:535-568.

Wardle, D. A., K. I. Bonner, and K. S. Nicholson. $1997 a$. Biodiversity and plant litter: experimental evidence which does not support the view that enhanced species richness improves ecosystem function. Oikos 79:247-258.

Wardle, D. A., and J. P. Grime. 2003. Biodiversity and stability of grassland ecosystem functioning. Oikos 100:622623. 
Wardle, D. A., G. Hörnberg, O. Zackrisson, M. Kalela-Brundin, and D. A. Coomes. 2003. Long-term effects of wildfire on ecosystem properties across an island area gradient. Science 300:972-975.

Wardle, D. A., M. A. Huston, J. P. Grime, F. Berendse, E. Garnier, W. K. Laurenroth, H. Setälä, and S. D. Wilson. $2000 \mathrm{~b}$. Biodiversity and ecosystem function: an issue in ecology. Bulletin of the Ecological Society of America 81: 235-239.

Wardle, D. A., O. Zackrisson, G. Hörnberg, and C. Gallet. $1997 \mathrm{~b}$. The influence of island area on ecosystem properties. Science 277:1296-1299.

Watson, J. W., and P. B. Eyzaguirre, editors. 2002. Home gardens and in situ conservation of plant genetic resources in farming systems. Proceedings of the Second International Home Gardens Workshop. International Plant Genetic Resources Institute, Rome, Witzenhausen, Germany.

Wedin, D., and D. Tilman. 1993. Competition among grasses along a nitrogen gradient: initial conditions and mechanisms of competition. Ecological Monographs 63:199-229.

Weiher, E., and P. Keddy. 1999a. Assembly rules as genera constraints on community composition. Pages 251-271 in E. Weiher and P. Keddy, editors. Ecological assembly rules perspectives, advances, retreats. Cambridge University Press, Cambridge, UK.

Weiher, E., and P. Keddy, editors. 1999b. Ecological assembly rules: perspectives, advances, retreats. Cambridge University Press, Cambridge, UK.

Westoby, M. 1998. A leaf-height-seed (LHS) plant ecology strategy scheme. Plant and Soil 199:213-227.

Whittaker, R. J., and E. Heegaard. 2003. What is the observed relationship between species richness and productivity? Ecology 84:3384-3389.
Williams, B. L. 1994. Interactions between tree species and their effects on nitrogen and phosphorus transformations in the forest floor. Pages 357-370 in T. J. B. Boyle and C. E. B. Boyle, editors. Biodiversity, temperate ecosystems, and global change. Springer-Verlag, Berlin, Germany.

Wilsey, B. J., and C. Potvin. 2000. Biodiversity and ecosystem functioning: importance of species evenness in an old field. Ecology 81:887-892.

Wilson, E. O. 1992. The diversity of life. Norton, New York, New York, USA.

Wilson, E. O., and E. O. Willis. 1975. Applied biogeography. Pages 522-534 in M. L. Cody and J. M. Diamond, editors. Ecology and evolution of communities. Belknap Press of Harvard University Press, Cambridge, Massachusetts, USA.

Wilson, J. B. 1999. Guilds, functional types and ecological groups. Oikos 86:507-522.

Wolters, V., et al. 2000. Effects of global changes on aboveand belowground biodiversity in terrestrial ecosystems: implications for ecosystem functioning. BioScience 50:10891098.

Yachi, S., and M. Loreau. 1999. Biodiversity and ecosystem productivity in a fluctuating environment: the insurance hypothesis. Proceeding of the National Academy of Sciences USA 96:1463-1468.

Zak, D. R., W. E. Holmes, D. C. White, A. D. Peacock, and D. Tilman. 2003. Plant diversity, soil microbial communities, and ecosystem function: are there any links? Ecology 84:2042-2050.

Zhu, Y., et al. 2000. Genetic diversity and disease control in rice. Nature 406:718-722.

Zimov, S. A., V. I. Chuprynin, A. P. Oreshko, F. S. Chapin, III, J. F. Reynolds, and M. C. Chapin. 1995. Steppe-tundra transition: a herbivore-driven biome shift at the end of the Pleistocene. American Naturalist 146:765-794. 